\title{
STUDY ON MICROMECHANICAL FRACTURE MODELS OF STRUCTURAL STEEL AND ITS WELDS
}

\author{
Xi-Yue Liu ${ }^{1}$, Yuan-Qing Wang ${ }^{2}$, Yi-Du Bu ${ }^{3, *}$ and Yang Guan ${ }^{4}$ \\ ${ }^{1}$ National University of Defense Technology \\ ${ }^{2}$ Tsinghua University \\ ${ }^{3}$ Beijing University of Technology \\ ${ }^{4}$ Zhuzong Real Estate Development Co., Ltd \\ *(Corresponding author: E-mail: yidubu@bjut.edu.cn)
}

\section{A B S T R A C T}

Steel structures have been widely used in constructions due to their advantages of lightweight, high strength, short construction time and high recycling and reuse potential. Fracture failure in steel structures should be prevented to avoid collapse of the whole structures. Micromechanical fracture models can capture the fracture initiation mechanisms and therefore can be used to predict ductile fractures in steel. Twelve smooth round bars were carried out to obtain the material properties and 36 notched round bars were tested to calibrate the parameters of stress modified critical strain (SMCS) model and the void growth model (VGM) for structural steels (Q235B and Q345B) and the corresponding welds. Specimens were extracted from the base metal, the weld metal and the heat affected zone (HAZ) to investigate fracture behaviour in different parts of the welded joint. Scanning electron microscope (SEM) measurements were taken and finite element models were developed to calibrate the models. The test results and calibrated parameters are reported. Moreover, the calibrated models are applied to analyses the fracture behaviour of welded joints and their accuracy are validated. The calibrated and validated models can be used for further numerical fracture analysis in welded steel structures.

\section{A R T I C LE H IS T O R Y}

$\begin{array}{ll}\text { Received: } & 15 \text { April } 2020 \\ \text { Revised: } & 15 \text { April } 2020 \\ \text { Accepted: } & 21 \text { November } 2020\end{array}$

\section{K E Y W O R D S}

Steel structure;

Fracture prediction;

Micromechanical models;

Tests;

Finite element analyses;

Parameter calibration

\section{Introduction}

Fracture failure in steel structures should be prevented to avoid collapse of the whole structures. Structural steel generally exhibits ductile fracture behaviour with significant plasticity. Conventional fracture mechanics, however, assumes pre-existing cracks with high strain constraint, offering better fit for brittle fracture with low plasticity. Moreover, the conventional fracture mechanic methods do not take triaxiality into consideration, thus it is not suitable to predict the fracture for welded steel connections or other welded steel components controlled by triaxial stress condition. Micromechanical facture models assume three stages of microvoid nucleation, void growth, and void coalescence, which capture the effect of stress and strain state on fracture behaviour and can be used in finite element analyses to predict the fracture initiation more accurately.

Earlier models ${ }^{[1]}$ for ductile failure assume homogenous continuum with no stress state. In 1969, Rice and Tracey ${ }^{[2]}$ investigated the influence of triaxial hydrostatic stresses on the process of micromechanical void coalescence analytically, which served as the basis of void growth model (VGM). In 1976, Hancock and Mackenzie ${ }^{[3]}$ carried out tests in different steels to determine the strain required to initiate ductile failure in multi-axial stress-states and proposed that void expansion and coalescence is related to orientation and stress triaxiality. Hancock and Cowling ${ }^{[4]}$ presented the failure mechanisms in three stages: micro void nucleation, growth, and coalescence. Later in 1983, Hancock and Brown ${ }^{[5]}$ conducted experiments and finite deformation stress analysis in a range of structural steels and proposed that the strain to initiate failure is related to the stress state. Similar models have been proposed and tested for various materials by Johnson and $\mathrm{Cook}^{[6]}$, Marini et al. ${ }^{[7]}$, Panontin and Sheppard ${ }^{[8]}$ and Bandstra et al. ${ }^{[9]}$. More recently in 2006, Kanvinde and Deierlein $^{[10]}$ carried out material tests and finite-element analyses for seven varieties of structural steels to validate the material dependent parameters. In 2006, $\mathrm{Chi}^{[11]}$ calibrated the toughness parameters of stress modified critical strain model (SMCS) model for mild A572 Grade 50 steel from a series of notched tensile tests. In 2010, Benzerga and Leblond ${ }^{[12]}$ examined the micromechanical models of various stages of ductile fracture and conducted fracture prediction by crack growth simulation. In 2010, Myers et al. ${ }^{[13]}$ conducted 23 uniaxial tensile tests and verified that the sample size was not significantly related to the toughness parameters of the SMCS model. In 2011, Wang et al. ${ }^{[14]}$ compared VGM , SMCS models and J-integral methods in the ductile fracture analysis of welded steel joints and found out that the VGM and SMCS models offered more accurate predictions. In 2012, Kossakowski ${ }^{[15]}$ conducted fracture prediction for S235JR steel using SMCS fracture criterion and concluded that using the characteristic length of the material as mesh size in finite element analysis offered better accuracy. In 2012, Liao et al. ${ }^{[16}$ conducted material tests on the base material of Q345 steel, weld deposit metal and heat affected zone, and calibrated the toughness parameters of VGM and SMCS model. Steel joint test data was used to verify the applicability of VGM and SMCS prediction. In 2013, Kiran et al. ${ }^{[17]}$ studied the ductile fracture behaviour of A992 steel under high stress triaxiality, and calibrated the toughness parameters of VGM and SMCS models. In 2015, Liu et al. ${ }^{[18]}$ and $\mathrm{Lu}^{[19]}$ calibrated the toughness parameters of VGM model, SMCS model for Q460C high-strength steel and Q235 steel, respectively.

Recent studies have focused on the toughness parameter calibration for different materials. With calibrated material dependent parameters, the micromechanical models can be used in ductile fracture prediction and offer good prediction. Q235B and Q345B are two most commonly used structural steels and previous studies have investigated the parameters separately. In this paper, the ductile fracture behaviour of the base metal, the weld metal and the heat affect zone for these two steels were studied and compared systematically. The micromechanical models of structural steels under monotonic loading were investigated, including the void growth model (VGM) and the stress modified critical strain model (SMCS). Material dependent parameters in the models were calibrated, including the toughness parameters $\eta_{\text {mon }}$ and $\gamma$. Scanning electron microscope (SEM) measurements were taken to determine the characteristic length $l^{*}$. Even though Q235B and Q345B are the most commonly used structural steels in China, the calibrations of the above three material dependent parameters for Q235B and Q345B welded steels is scarce. The calibrated micromechanical models can be used for further numerical fracture analysis of different types of welded steel joints and offer more accurate prediction in fractural behaviour.

\section{Theory}

Previous studies show that fracture initiation is dependent on both the strain state and the stress triaxiality of the material. Micromechanical model can be used to capture the initiation of the cracks and to predict the fracture failure of the component. The models reveal the interaction between stress and strain state and combine micromechanical level void deformation with crack initiation. Two micromechanical models have been considered in this paper and are described below.

\subsection{Void growth model (VGM model)}

In 1969 Rice and Tracey ${ }^{[2]}$ deduced the analytical solutions in elastic-plastic materials, considering the influence of stress triaxiality and 
plastic strain on microvoid expansion of individual cylindrical and spherical void. Expanding on the derivations a critical value $\eta_{\text {mon }}$ is defined to represent the critical state of crack initiation, corresponding to the state of void coalescence. $\eta_{\text {mon }}$ is defined as follow:

$\eta_{\text {mon }}=\frac{\ln \left(\frac{R}{R_{0}}\right)_{\text {critical }}}{C}=\int_{0}^{\varepsilon_{p}} \exp (1.5 T) \cdot d \varepsilon_{p}$

where $R$ is radius at fracture, $R_{0}$ is the initial radius, $T$ is the triaxiality of the stress and $T=\sigma_{m} / \sigma_{e}, \sigma_{m}$ is the mean stress and $\sigma_{\mathrm{e}}$ is the von Mises stress. $\eta_{\text {mon }}$ is a material dependent parameter which determines the toughness of the material. A larger value of $\eta_{\text {mon }}$ shows better ductility of a material. $\eta_{\text {mon }}$ can be calibrated from notched bar material tests. The fracture criterion of void growth model is expressed as fracture index $F I_{\mathrm{VGM}}$ :

$F I_{\mathrm{VGM}}=\int_{0}^{\varepsilon_{p}^{\text {cinitacl }}} \exp (1.5 T) d \varepsilon_{p}-\eta_{\mathrm{mon}}>0$

where $\varepsilon_{p}^{\text {critical }}$ is the equivalent plastic strain at the critical state. $F I_{\mathrm{VGM}}=0$ represents the critical state while $F I_{\mathrm{VGM}}>0$ indicates the initiation of the fracture.

\subsection{Stress modified critical strain (SMCS model)}

In VGM, the stress triaxiality is integrated with respect to the material's plastic strain throughout the loading process. In reality the variation of the stress triaxiality throughout the loading process is normally small, therefore the integral term can be substituted with a material dependent constant, as shown in Eq. 3.

$\ln \left(\frac{R}{R_{0}}\right)_{\text {monoionic }}^{\text {critical }}=C \exp \left(\frac{1.5 \sigma_{\mathrm{m}}}{\sigma_{\mathrm{c}}}\right) \cdot \varepsilon_{p}^{\text {critical }}$

The critical equivalent plastic strain $\varepsilon_{p}^{c r i t i c a l}$ and toughness parameter $\gamma$ can be expressed as follow:

$\gamma=\frac{\ln \left(\frac{R}{R_{0}}\right)_{\text {monotonic }}^{\text {critical }}}{C}=\varepsilon_{p}^{\text {critical }} \cdot \exp (1.5 T)$

The fracture criterion of SMCS is expressed as fracture index $F I_{\text {SMCS }}$ :
$F I_{\text {SMCS }}=\varepsilon_{p}-\gamma \cdot \exp (-1.5 T)>0$

where SMCS is the fracture criterion. $F I_{\mathrm{SMCS}}=0$ represents the critical state while $F I_{\mathrm{SMCS}}>0$ indicates the initiation of the fracture.

The VGM model considers the variation of stress triaxiality during the loading process, offering a more accurate theoretical solution. The SMCS model which assumes that the stress triaxiality does not change with respect to equivalent plastic strain offers a more efficient calculation. It is worth noting that the microstructural void growth and coalescence should also be considered, and failure criterion can only be reached, for both VGM and SMCS, if multiple material points within a certain length scale reach the fracture criterion. This length serves as another parameter, known as characteristic length $l^{*} . l^{*}$ is based on the microstructure of the material, thus can be measured by a microscope.

\section{Ductile fracture tests}

\subsection{Material}

The materials studied in this paper are two of the most commonly used structural steel materials in China: Q235B and Q345B, with nominal yield strength of $235 \mathrm{MPa}$ and $345 \mathrm{MPa}$, respectively. All specimens were extracted from $24 \mathrm{~mm}$ thick plates. The chemical compositions of the plate material, as provided in the manufacturer's mill certificates, are reported in Tables 1 and 2. Two steel plates of $24 \mathrm{~mm}$ were connected with full penetration butt weld as shown in Fig. 1. Welding parameters are listed in Table 3. Specimens from three parts were extracted and investigated: base metal, weld metal and heat affected zone. The relative position of the coupons and the weld is described later.

\section{Table 1}

Chemical composition of Q235B steel

\begin{tabular}{cccccc}
\hline \multicolumn{7}{c}{ Chemical composition quality score $/ \%$} \\
\hline $\mathrm{C}$ & $\mathrm{Mn}$ & $\mathrm{Si}$ & $\mathrm{P}$ & $\mathrm{S}$ & $\mathrm{Ni}$ \\
\hline$\leq 0.2$ & $0.3 \sim 0.7$ & $\leq 0.35$ & $\leq 0.045$ & $\leq 0.045$ & $\leq 0.80$ \\
\hline
\end{tabular}

Table 2

Chemical composition of Q345B steel

\begin{tabular}{cccccccccc}
\hline \multicolumn{10}{c}{ Chemical composition quality score $/ \%$} \\
\hline $\mathrm{C}$ & $\mathrm{Mn}$ & $\mathrm{Si}$ & $\mathrm{P}$ & $\mathrm{S}$ & $\mathrm{V}$ & $\mathrm{Nb}$ & $\mathrm{Ti}$ & $\mathrm{Al}$ \\
\hline$\leq 0$. & $1.00 \sim 1$. & $\leq 0.5$ & $\leq 0.0$ & $\leq 0.0$ & $0.02 \sim 0$. & $0.015 \sim 0.0$ & $0.02 \sim 0$. & $\geq 0.0$ \\
\hline
\end{tabular}

Table 3

Welding Process Parameters

\begin{tabular}{|c|c|c|c|c|c|c|c|c|}
\hline Welding method & Position of welding & Wire model & $\begin{array}{l}\text { Wire diameter } \\
\qquad / \mathrm{mm}\end{array}$ & Gas & $\begin{array}{c}\text { Electric current } \\
\text { /A }\end{array}$ & Voltage /V & $\begin{array}{c}\text { Pre-heat } \\
\text { temperature } /{ }^{\circ} \mathrm{C}\end{array}$ & $\begin{array}{c}\text { Welding speed } \\
/ \mathrm{cm} / \mathrm{min}\end{array}$ \\
\hline $\begin{array}{c}\text { Gas shielded } \\
\text { welding }\end{array}$ & Flat welding & E4303/ER50-6 & $\phi_{1.2}$ & $\mathrm{CO}_{2}$ & 260 & 30 & 60 & $20-35$ \\
\hline
\end{tabular}

\subsection{Smooth round bar tensile tests}

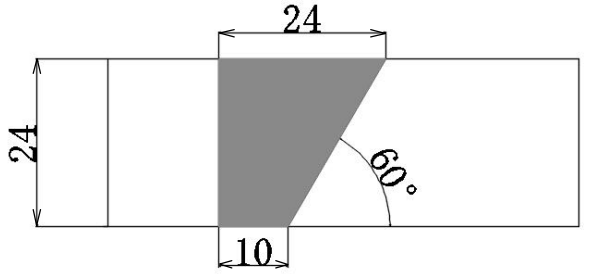

Fig. 1 Schematic drawing of the butt weld $(\mathrm{mm})$

\subsubsection{Test specimens and test setup}

Standard round bar specimens were designed according to the Chinese standard GB/T228.1-2010 $0^{[20]}$ and extracted from the base metal, the weld metal, and the heat affected zone (HAZ), which is within $10 \mathrm{~mm}$ from the edge of the welding seam, as shown in Fig. 2. For each type of coupon two repetitive tests were carried out and the average response were used. The tested coupons are listed in Table 4. The specimens are designated with three letters, with the first two representing the position of the coupon (BM for base metal, WM for weld metal and HM for heat affected zone) and the last letter representing the material of the coupon ( $\mathrm{L}$ for Q235B and $\mathrm{H}$ for Q345B). The geometries of the coupons are presented in Fig. 3. Note that the coupons from $\mathrm{HAZ}$ were designed smaller so only material in HAZ was considered. 


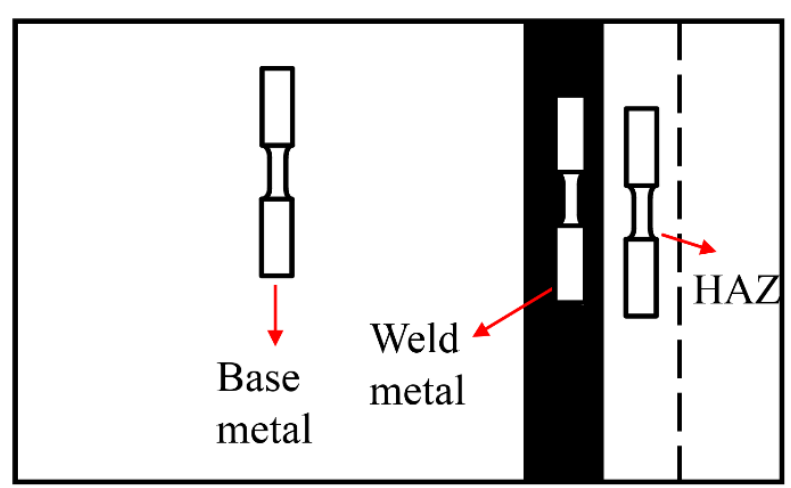

Table 4

List of test coupons

\begin{tabular}{ccccc}
\hline Position & Material & ID & Gauge length $(\mathrm{mm})$ & Quantity \\
\hline \multirow{2}{*}{ Base metal } & Q235B & BML & 12.5 & 2 \\
\cline { 2 - 5 } & Q345B & BMH & 12.5 & 2 \\
\hline \multirow{2}{*}{ Weld metal } & Q235B & WML & 12.5 & 2 \\
\cline { 2 - 5 } & Q345B & WMH & 12.5 & 2 \\
\hline \multirow{2}{*}{ Heat affected } & Q235B & HML & 25.0 & 2 \\
\cline { 2 - 5 } zone & Q345B & HMH & 25.0 & 2 \\
\hline
\end{tabular}

Fig. 2 Specimens layout

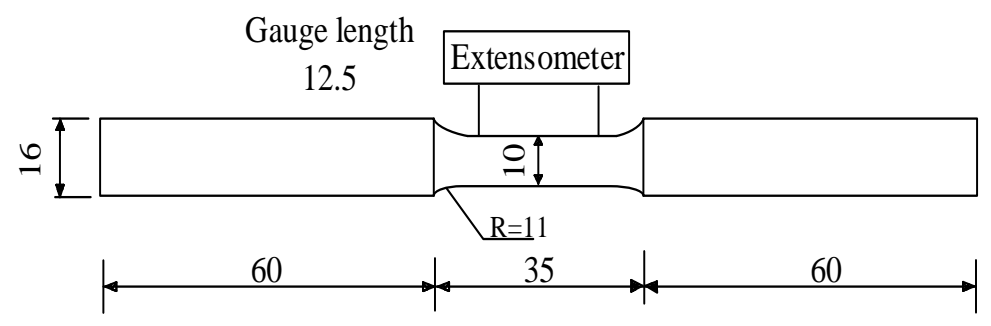

(a) Dimensions of base metal and weld metal specimens ( $\mathrm{mm}$ )

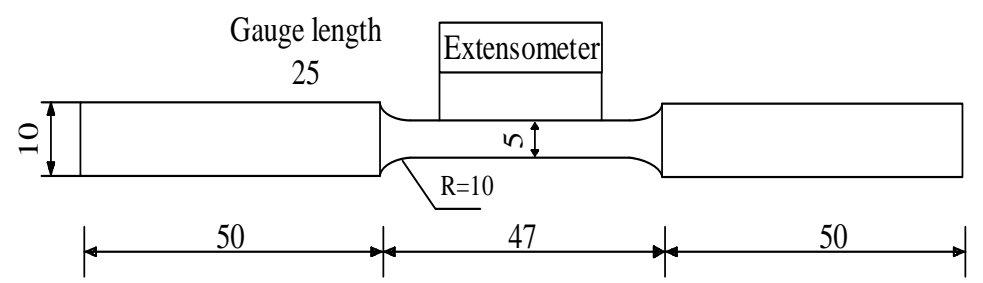

(b) Dimensions of HAZ specimens (mm)

Fig. 3 Standard round bar specimen dimensions

The experiments were conducted in the State Key Laboratory of Metal Matrix Composites of Shanghai Jiao Tong University. All tensile tests were conducted using a $100 \mathrm{kN}$ Zwick Roell universal material testing machine, following the procedure set out in the Chinese standard GB/T228.1-2010 ${ }^{[20]}$. A two-stage loading protocol was used to capture the initiation of the fracture, with a loading rate of $0.5 \mathrm{~mm} / \mathrm{min}$ prior to the yielding point of the material and $1.0 \mathrm{~mm} / \mathrm{min}$ afterwards. In previous studies, the extensometer is often taken off the specimen after the onset of necking to avoid damage from vibration upon fracture. The extensometer used herein is connected with springs to protect it from the vibration damage caused by the sudden failure of the specimen, thus the whole process can be captured. The gauge length was $12.5 \mathrm{~mm}$. The test loading device and measurement are shown in Fig. 4.

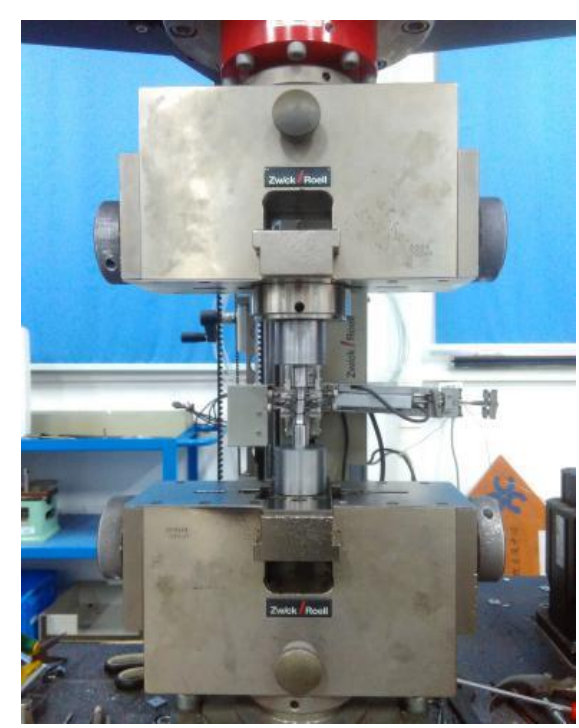

(a) Loading device

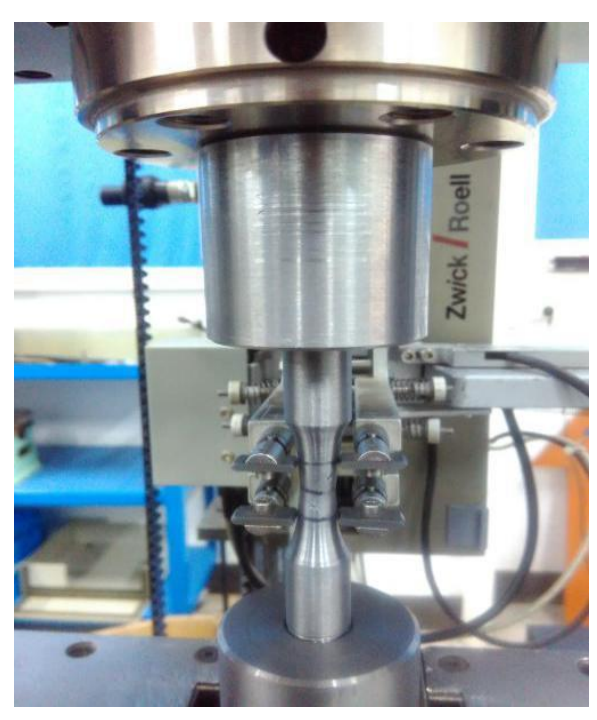

(b) Extensometer 


\subsubsection{Test results}

The stress and strain curves obtained during the test are shown in Fig. 5. Only one typical stress-strain curve for each type of the specimens was presented while the obtained mechanical properties were averaged and listed in
Table 5, including the yield strength $\sigma_{\mathrm{y}}$, tensile strength $\sigma_{\mathrm{u}}$, elastic modulus $E$, diameter at fracture $d_{\mathrm{f}}$ which was measured by a microscope after the tests, as shown in Fig. 6, fracture load $N_{\mathrm{f}}$, fracture stress $\sigma_{\text {true,f, }}$ and the calculated corresponding fracture strain $\varepsilon_{\text {true,f. }}$

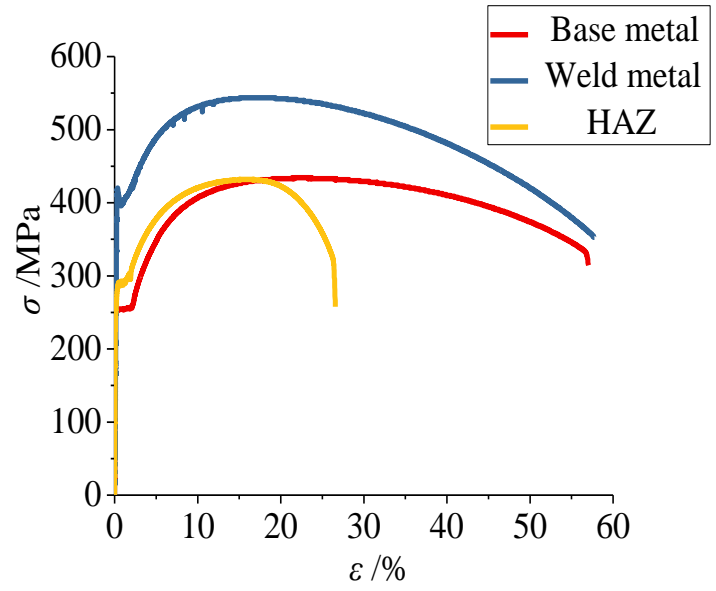

(a) Q235B

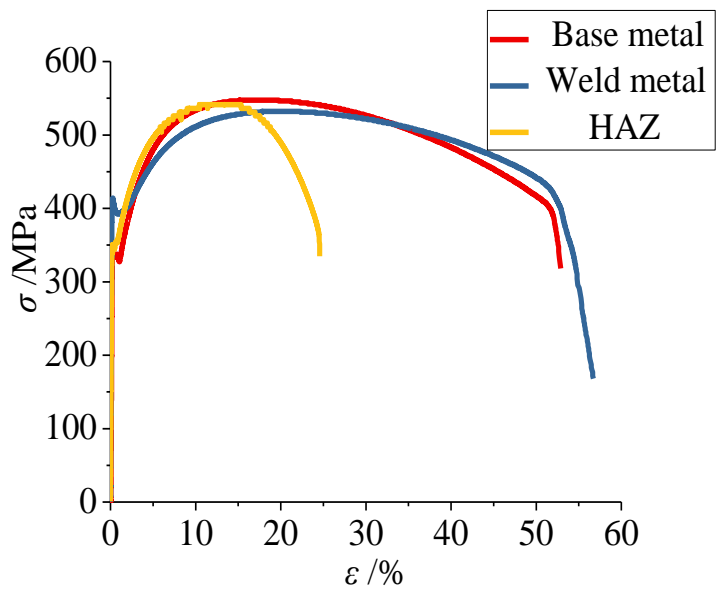

(b) Q345B

Fig. 5 Stress-strain curves

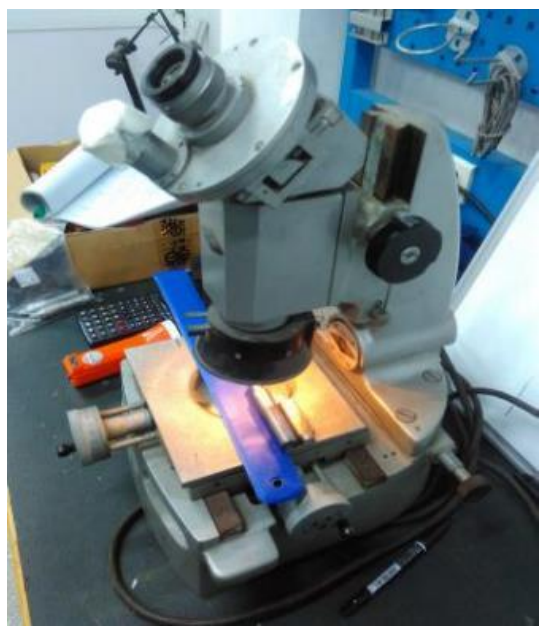

Fig. 6 Microscope setup

Table 5

Measured material properties from tensile coupon tests

\begin{tabular}{|c|c|c|c|c|c|c|c|c|c|}
\hline Material & Position & ID & $\sigma_{\mathrm{y}} / \mathrm{MPa}$ & $\sigma_{\mathrm{u}} / \mathrm{Mpa}$ & $E / \mathrm{Mpa}$ & $d_{\mathrm{f}} / \mathrm{mm}$ & $N_{\mathrm{f}} / \mathrm{kN}$ & $\sigma_{\text {true }, \mathrm{f}} / \mathrm{Mpa}$ & $\varepsilon_{\text {ture, }}$ \\
\hline \multirow{9}{*}{ Q235B } & \multirow{3}{*}{$\begin{array}{l}\text { Base } \\
\text { metal }\end{array}$} & BML-1 & 258.03 & 437.96 & 219164 & 6.339 & 25.10 & 795.42 & 0.903 \\
\hline & & BML-2 & 253.78 & 427.16 & 217251 & 5.966 & 26.20 & 937.19 & 1.031 \\
\hline & & Average & 255.91 & 432.56 & 218208 & 6.153 & 25.65 & 866.31 & 0.967 \\
\hline & \multirow{3}{*}{$\begin{array}{l}\text { Weld } \\
\text { metal }\end{array}$} & WML-1 & 396.64 & 544.59 & 208176 & 5.410 & 27.70 & 1205.02 & 1.227 \\
\hline & & WML-2 & 398.40 & 547.35 & 203673 & 5.407 & 28.40 & 1237.08 & 1.230 \\
\hline & & Average & 397.52 & 545.97 & 205924 & 5.559 & 28.05 & 1159.35 & 1.170 \\
\hline & \multirow{3}{*}{ HAZ } & HML-1 & 287.58 & 433.40 & 115861 & 3.047 & 6.36 & 872.50 & 1.000 \\
\hline & & HML-2 & 301.10 & 448.57 & 114105 & 3.044 & 6.48 & 890.66 & 0.967 \\
\hline & & Average & 295.09 & 437.95 & 114983 & 3.058 & 6.32 & 860.80 & 0.976 \\
\hline \multirow{9}{*}{ Q345B } & \multirow{3}{*}{$\begin{array}{l}\text { Base } \\
\text { metal }\end{array}$} & BMH-1 & 346.64 & 558.30 & 184330 & 6.023 & 31.01 & 1088.18 & 0.994 \\
\hline & & BMH-2 & 342.57 & 560.22 & 196011 & 5.991 & 31.30 & 1110.38 & 1.002 \\
\hline & & Average & 344.61 & 559.26 & 190171 & 6.007 & 31.15 & 1099.28 & 0.998 \\
\hline & \multirow{3}{*}{ Weld metal } & WMH-2 & 390.10 & 526.10 & 212135 & 6.209 & 31.90 & 1053.50 & 0.955 \\
\hline & & WMH-3 & 394.60 & 535.54 & 205078 & 6.340 & 32.60 & 1032.74 & 0.905 \\
\hline & & Average & 392.35 & 530.82 & 208607 & 6.275 & 32.25 & 1043.12 & 0.930 \\
\hline & \multirow{3}{*}{ HAZ } & НMH-1 & 353.06 & 541.30 & 112120 & 2.729 & 7.18 & 1227.60 & 1.218 \\
\hline & & HMH-2 & 358.42 & 559.24 & 118395 & 2.928 & 7.69 & 1142.67 & 1.070 \\
\hline & & Average & 355.74 & 550.27 & 115258 & 2.829 & 7.44 & 1185.14 & 1.144 \\
\hline
\end{tabular}


The measured engineering stress-strain responses were converted into true stress $\sigma_{\text {true }}$ and $\log$ plastic strain $\varepsilon_{\text {p }}$ using Eqs. 6 and 7

$\varepsilon_{\text {true }}=\ln \left(1+\varepsilon_{\text {eng }}\right)$

$\sigma_{\text {true }}=\sigma_{\text {eng }}\left(1+\varepsilon_{\text {eng }}\right)$

$\varepsilon_{p}=\varepsilon_{\text {true }}-\frac{\sigma_{\text {true }}}{E}$

where $\sigma_{\text {eng }}$ and $\varepsilon_{\text {eng }}$ are the engineering stress and strain, respectively while $E$ is the Young's modulus. From the onset of necking during the tensile tests, the elongation was no longer uniform within the gauge length but concentrated in the necking area. Therefore, the stress-strain curves obtained from the tests were used till the onset of necking and extended to the point of fracture, which can be calculated with Eqs. 9 and 10.

$\sigma_{\text {true }, f}=P_{f} /\left(\pi d_{f}^{2} / 4\right)$

$\varepsilon_{\text {true }, f}=\ln \left[\left(d_{0} / d_{f}\right)^{2}\right]$

where $d_{f}$ is the fracture diameter and was measured by a microscope, as shown in Fig. 6. The obtained true stress-plastic strain response was extended to fracture and is shown in Fig. 7 and was later input into finite element analyses software in multi-linear form.

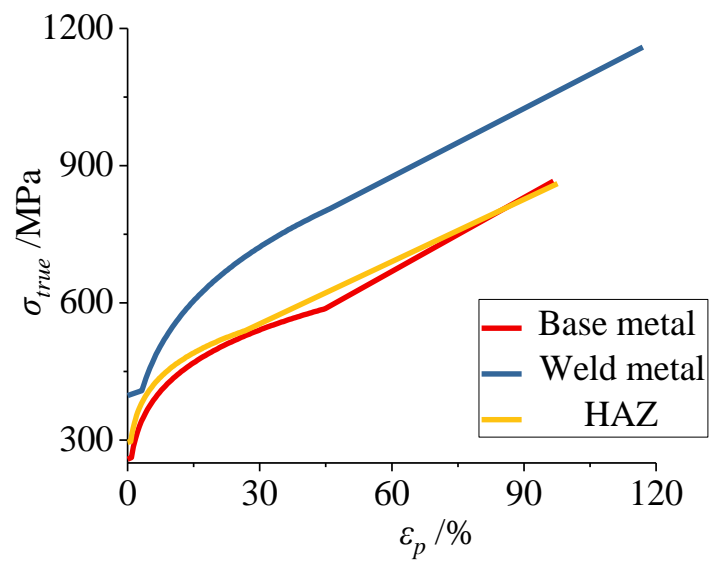

(a) Q235B

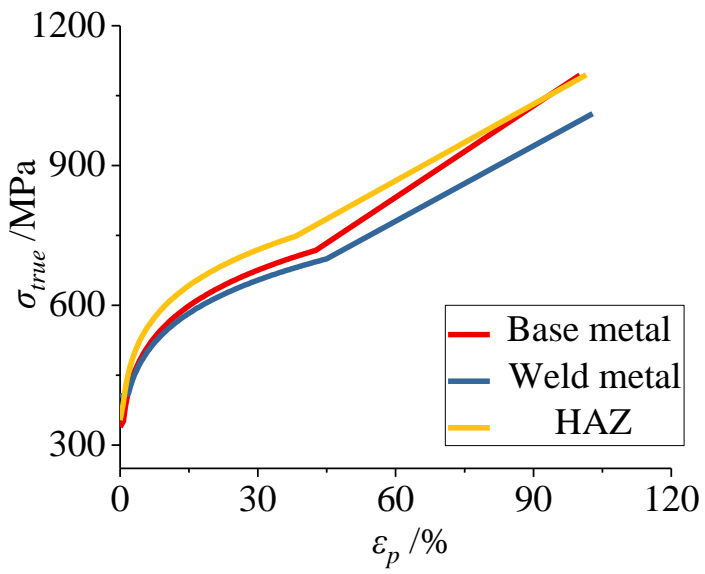

(b) Q345B

Fig. 7 True stress-plastic strain curves

\subsubsection{Fracture surface analysis}

Scanning electron microscope (SEM) measurements were taken at the Electron Microscopy Scanning Laboratory of School of Materials Science and Technology, Tsinghua University. Scanning electron microscope Quanta FEG 450 was used to observe the crystal shapes and fracture morphologies of all tested samples.

The macroscopic morphology of a typical fracture section is shown in Fig. 8. The fracture surface is composed of three parts: fibre zone, radiation zone, and shear lip zone, which corresponds to crack initiation zone, crack propagation zone, and shear fracture zone ${ }^{[19,21]}$. The fibre zone is located at the centre of the fracture. The macroscopic morphology of this zone shows a sawtooth fracture surface formed by microscopic voids. The radiation zone shows the rapid and unstable crack propagation. The out edge of the fracture surface is the shear lip zone, where the material fractured under shear force, with a smooth surface. The morphology shows that crack initiated from the centre and propagated through the whole section.

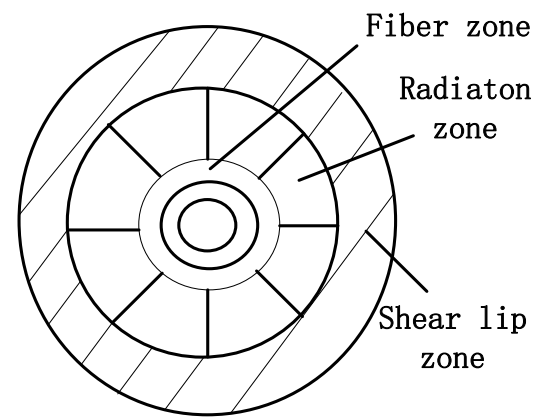

(a) Schematic drawing of the fracture section

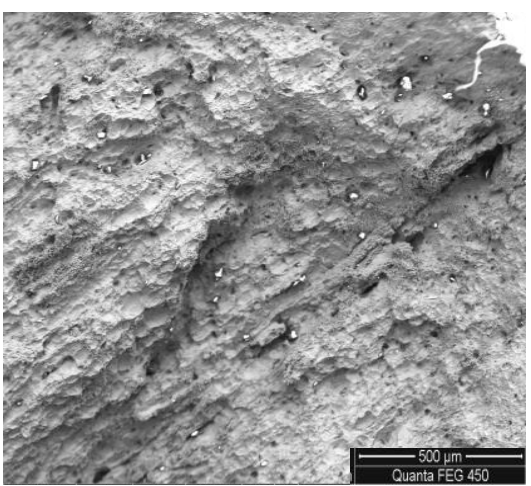

(b) Fibre zone fracture morphology

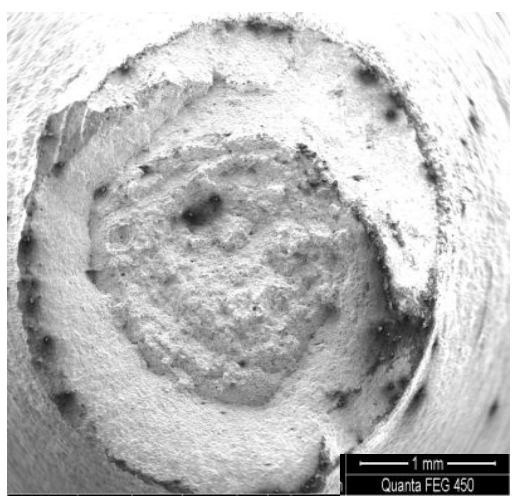

(c) Fracture section morphology

Fig. 8 Macroscopic fracture morphology

The commonly used structure steel often experiences ductile fracture with high level of plastic deformation. The microscopic morphology of a typical fracture surface is shown in Fig. 9. Dimples with different shapes, sizes, and depths can be observed on the fracture surface. The size and depth of the dimples are related to the stress state and the number of void nucleation. The dimples observed from the centre of fracture surface are mostly large and deep, showing good plasticity of the Q235B and Q345B. 

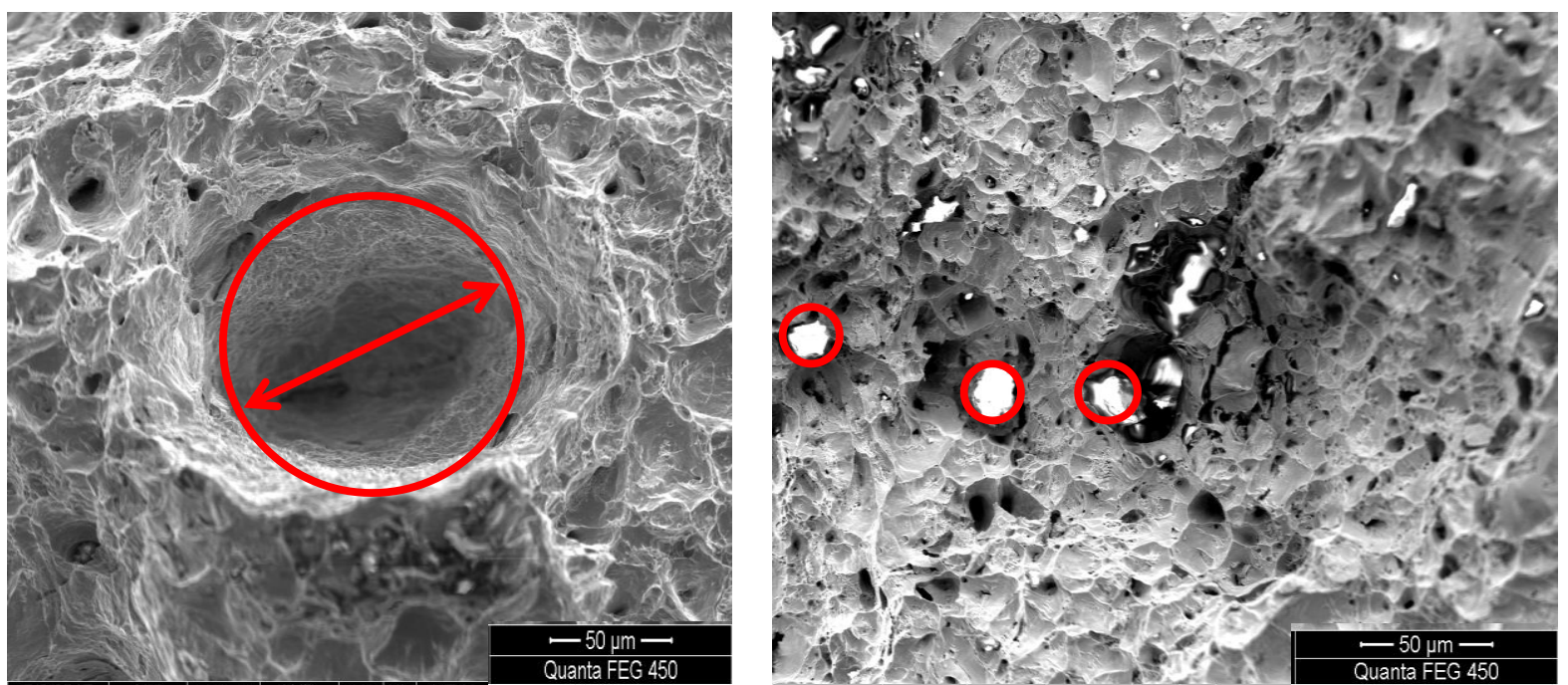

Fig. 9 Scanning electron microscope morphology

\subsection{Smooth-notched tensile test (SNTT)}

\subsubsection{Test specimens and test setup}

Smooth-notched tensile coupons were extracted from steel Q235B and Q345B welded plates at the positions of base metal, weld metal and HAZ. Three notch radii $R, 1.25,2.50$ and $5.00 \mathrm{~mm}$ were designed to consider different stress triaxiality conditions. The geometry of notched specimens is shown in Fig. 10, while the relative positions of specimens on the welded plate are shown in Fig. 11. Two repetitive tests were carried out for each type of coupon and the average response were used later on. A total of 36 specimens were carried out. All specimens were tested using the Zwick universal material testing machine and the whole stress-strain response was recorded until fracture. The test setup is shown in Fig. 12.

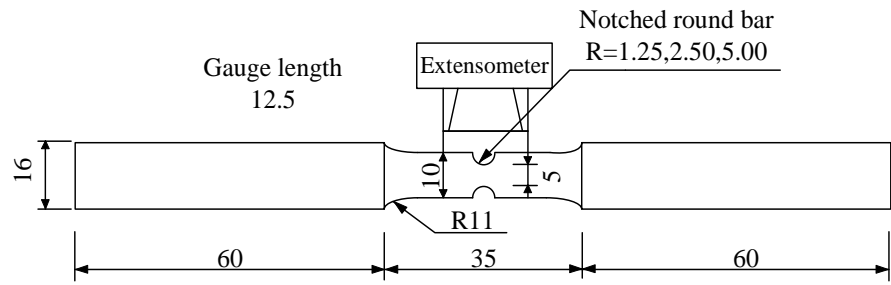

Fig. 10 Geometry of notched round bar specimen

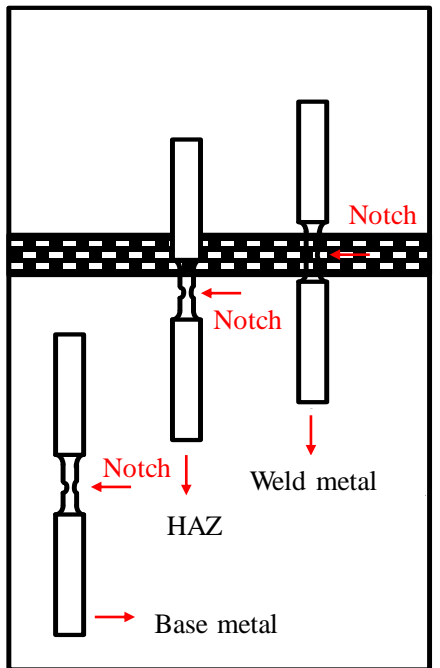

Fig. 11 Specimens layout

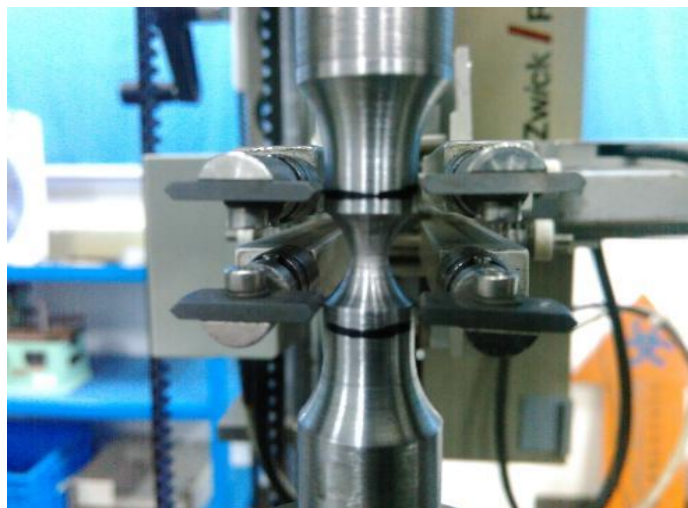

Fig. 12 Test setup

\subsubsection{Test results}

The load-displacement curves obtained from the notched bar tensile tests are shown in Fig. 13. It can be observed that all the curves have a sudden change in slope, the point with slope discontinuity is taken as the fracture initiation point. The displacement at this point was later used in the finite element analysis for the micromechanical model calibration. The obtained test results including ultimate load $N_{\mathrm{u}}$, fracture load $N_{\mathrm{f}}$ and fracture displacement $\delta_{\mathrm{f}}$ are summarised in Tables 6 and 7, for Q235B and Q345B, respectively. $d_{0}$ represents the diameter of the specimens prior to the tests. The specimens are designated with 4 letters here: the first one represents the position of the coupon (B for base metal, W for weld metal and $\mathrm{H}$ for heat affected zone); the second one represents the size of the notch radius in $\mathrm{mm}$ ( $\mathrm{S}$ for $1.25, \mathrm{M}$ for 2.50 and $\mathrm{L}$ for 5.00); the third letter $\mathrm{M}$ represents monotonic loading; the last one represents the material of the coupon (L for Q235B and H for Q345B). According to the experimental results, it can be concluded that with the increase of the notch radius of the test piece, the yield load and ultimate load of the test piece both decreases, and the displacement of the fracture increases, indicating that the larger the notch radius, the better the test piece toughness. 


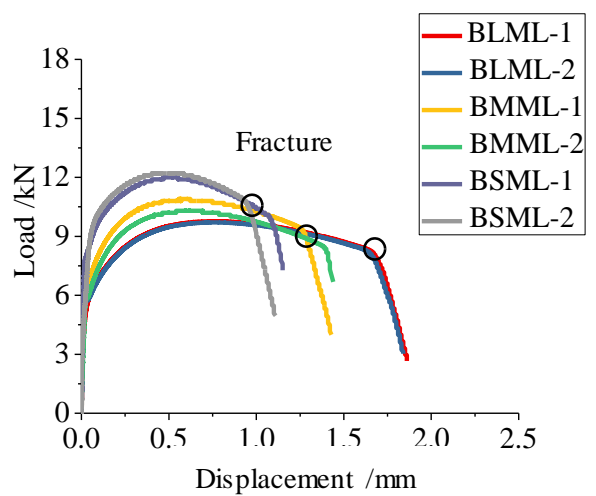

(a) Q235B base metal

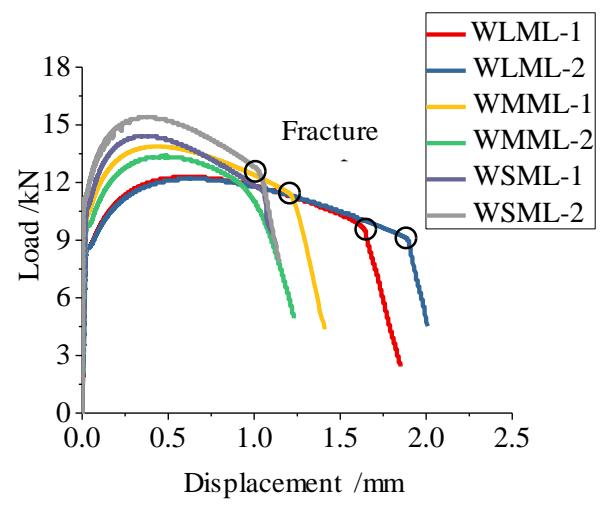

(c) Q235B weld metal

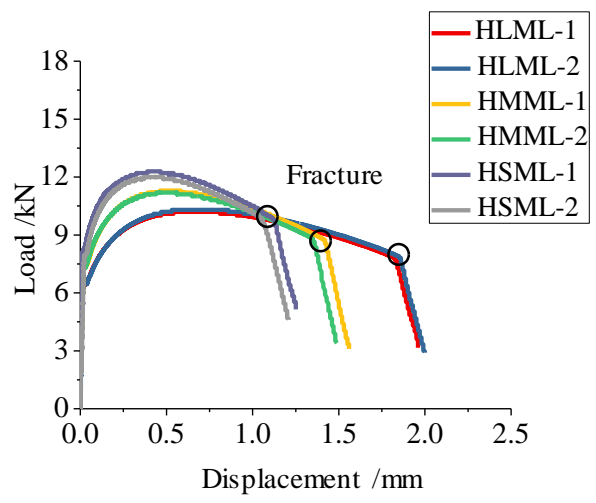

(e) Q235B HAZ

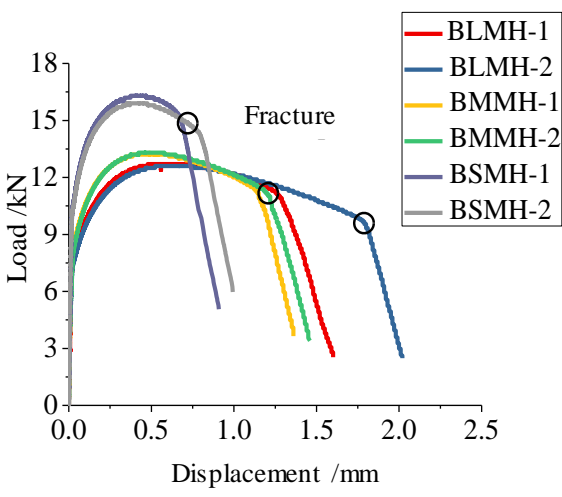

(b) Q345B base metal

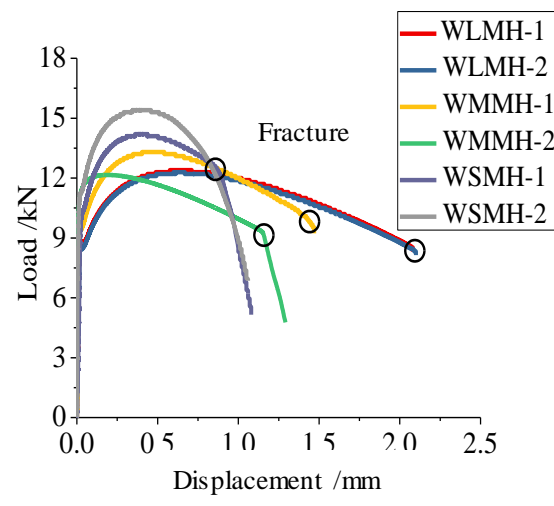

(d) Q345B weld metal

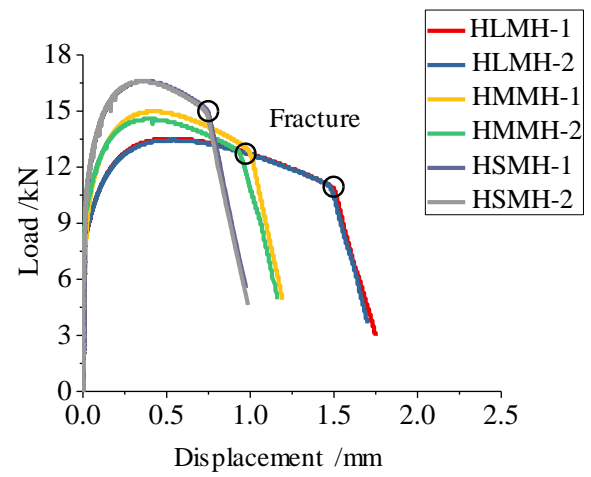

(f) Q345B HAZ

Fig. 13 Load-displacement curves

Table 6

Experimental results of Q235B steel

\begin{tabular}{|c|c|c|c|c|c|c|}
\hline Position & $R / \mathrm{mm}$ & ID & $d_{f} / d_{0}$ & $\delta_{f} / \mathrm{mm}$ & $N_{\mathrm{f}} / \mathrm{kN}$ & $N_{\mathrm{u}} / \mathrm{kN}$ \\
\hline \multirow{6}{*}{ Base metal } & \multirow{2}{*}{1.25} & BSML-1 & 0.768 & 1.08 & 10.11 & 12.00 \\
\hline & & BSML-2 & 0.762 & 0.94 & 10.90 & 12.20 \\
\hline & \multirow{2}{*}{2.50} & BMML-1 & 0.756 & 1.27 & 9.30 & 10.90 \\
\hline & & BMML-2 & 0.759 & 1.40 & 8.36 & 10.30 \\
\hline & \multirow{2}{*}{5.00} & BLML-1 & 0.699 & 1.66 & 8.25 & 9.77 \\
\hline & & BLML-2 & 0.722 & 1.65 & 8.18 & 9.71 \\
\hline \multirow{6}{*}{ Weld metal } & \multirow{2}{*}{1.25} & WSML-1 & 0.748 & 1.06 & 11.50 & 14.40 \\
\hline & & WSML-2 & 0.699 & 1.03 & 12.60 & 15.40 \\
\hline & \multirow{2}{*}{2.50} & WMML-1 & 0.694 & 1.22 & 10.30 & 13.40 \\
\hline & & WMML-2 & 0.711 & 1.04 & 11.36 & 13.88 \\
\hline & \multirow{2}{*}{5.00} & WLML-1 & 0.665 & 1.65 & 9.48 & 12.30 \\
\hline & & WLML-2 & 0.621 & 1.89 & 9.11 & 12.20 \\
\hline \multirow{3}{*}{ HAZ } & \multirow{2}{*}{1.25} & HSML-1 & 0.735 & 1.13 & 9.75 & 12.30 \\
\hline & & HSML-2 & 0.703 & 1.06 & 9.90 & 12.00 \\
\hline & 2.50 & HMML-1 & 0.682 & 1.42 & 8.74 & 11.30 \\
\hline
\end{tabular}




\begin{tabular}{llllll} 
& HMML-2 & 0.679 & 1.35 & 8.81 & 11.20 \\
\hline \multirow{2}{*}{5.00} & HLML-1 & 0.667 & 1.83 & 7.78 & 10.20 \\
\cline { 2 - 7 } & HLML-2 & 0.671 & 1.86 & 7.80 & 10.30 \\
\hline
\end{tabular}

Table 7

Experimental results of Q345B steel

\begin{tabular}{|c|c|c|c|c|c|c|}
\hline Position & $R / \mathrm{mm}$ & ID & $d_{f} / d_{0}$ & $\delta_{f} / \mathrm{mm}$ & $N_{\mathrm{f}} / \mathrm{kN}$ & $N_{\mathrm{u}} / \mathrm{kN}$ \\
\hline \multirow{6}{*}{ Base Metal } & \multirow{2}{*}{1.25} & BSMH-1 & 0.820 & 0.69 & 14.70 & 16.30 \\
\hline & & BSMH-2 & 0.760 & 0.80 & 14.40 & 15.90 \\
\hline & \multirow{2}{*}{2.50} & BMMH-1 & 0.730 & 1.15 & 11.20 & 13.20 \\
\hline & & BMMH-2 & 0.700 & 1.22 & 11.00 & 13.30 \\
\hline & \multirow{2}{*}{5.00} & BLMH-1 & 0.730 & 1.29 & 11.00 & 12.70 \\
\hline & & BLMH-2 & 0.730 & 1.79 & 9.67 & 12.60 \\
\hline \multirow{6}{*}{ Weld metal } & \multirow{2}{*}{1.25} & WSMH-1 & 0.756 & 0.89 & 12.10 & 14.20 \\
\hline & & WSMH-2 & 0.787 & 0.90 & 11.50 & 15.40 \\
\hline & \multirow{2}{*}{2.50} & WMMH-1 & 0.563 & 1.15 & 9.24 & 12.20 \\
\hline & & WMMH-2 & 0.548 & 1.42 & 9.98 & 13.30 \\
\hline & \multirow{2}{*}{5.00} & WLMH-1 & 0.578 & 2.08 & 8.53 & 12.40 \\
\hline & & WLMH-2 & 0.601 & 2.10 & 8.32 & 12.30 \\
\hline \multirow{6}{*}{ HAZ } & \multirow{2}{*}{1.25} & HSMH-1 & 0.769 & 0.75 & 15.00 & 16.60 \\
\hline & & HSMH-2 & 0.770 & 0.75 & 14.80 & 16.60 \\
\hline & \multirow{2}{*}{2.50} & НMМН-1 & 0.730 & 1.00 & 12.80 & 15.00 \\
\hline & & HMMH-2 & 0.740 & 0.94 & 12.80 & 14.60 \\
\hline & \multirow{2}{*}{5.00} & HLMH-1 & 0.674 & 1.50 & 10.90 & 13.50 \\
\hline & & HLMH-2 & 0.685 & 1.48 & 11.00 & 13.50 \\
\hline
\end{tabular}

The reduction in area was calculated from the test results. Together with the fracture displacement and ultimate load, the comparisons are summarised in Fig. 14, where the average value of each notch size is used. It can be seen

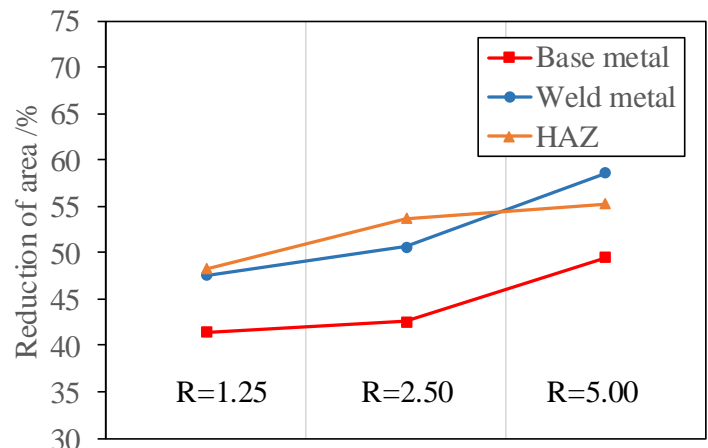

(a) Q235B reduction of area comparisons

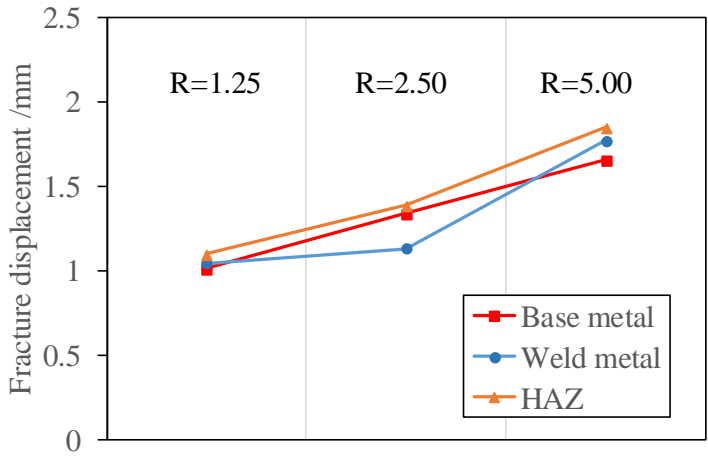

(c) Q235B displacement comparisons that for most specimens the reduction in area increases with increase notch size, while the percentage reduction in area for the weld metal of Q345B is generally higher, showing better ductility.

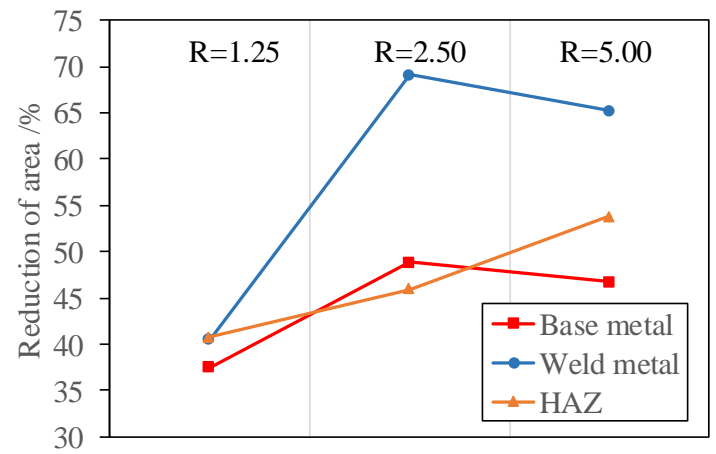

(b) Q345B reduction of area comparisons

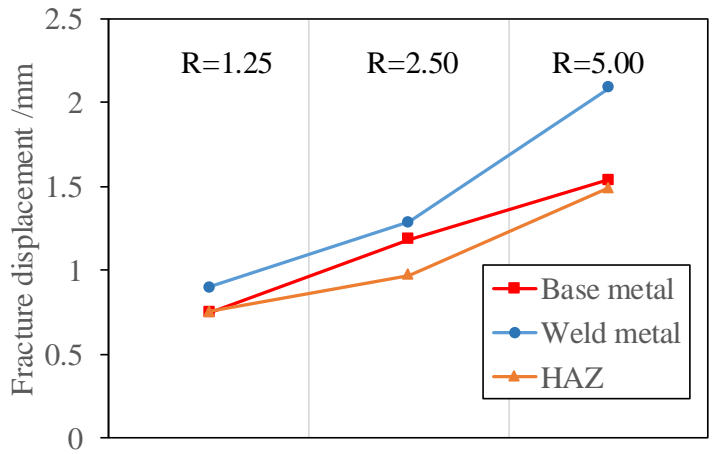

(d) Q345B displacement comparisons 


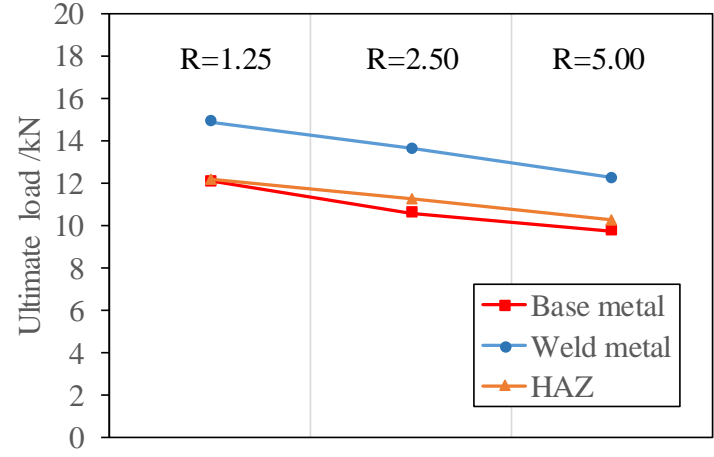

(e) Q235B load comparisons

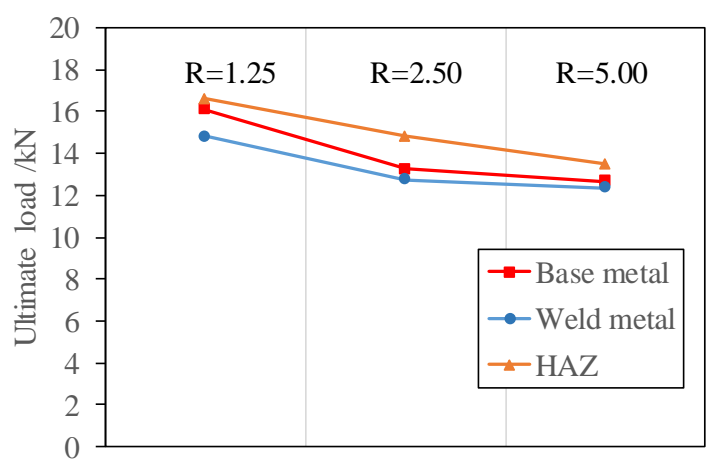

(f) Q345B load comparisons

Fig. 14 Test results comparisons

According to the results of the notch round bar tensile tests in Fig. 14, it can be seen that: (1) As the radius of the notch of the round bar increases, the ultimate load decreases, while the displacement at the time of failure increases, showing the equivalent plastic strain increases with the triaxiality decreases. (2) In general, the tensile strength and plasticity of weld region for Q235B steel are higher than that of base metal, showing good welding performance. (3) Sedimentary cladding metal of Q345B steel is more plastic than the base metal, while the tensile strength is slightly lower than that of the base metal, and the tensile strength of heat affected zone is enhanced. The properties of the deposited metal are slightly different from those of the Q235 B weld. The reason may be that the weld pool is wider. The fusion of Q345 B steel and weld seam is weaker than that of Q235 B weld. The heat affected zone of the heated edge is prone to hardening under the influence of thermal cycling.

\subsubsection{Macroscopic fracture analysis}

Same as in 3.3.1 scanning electron microscope (SEM) measurements were taken for all specimens. The upper and lower limits of the characteristic length $l^{*}$, a parameter of microscopic mechanism models, were obtained from the measurements.
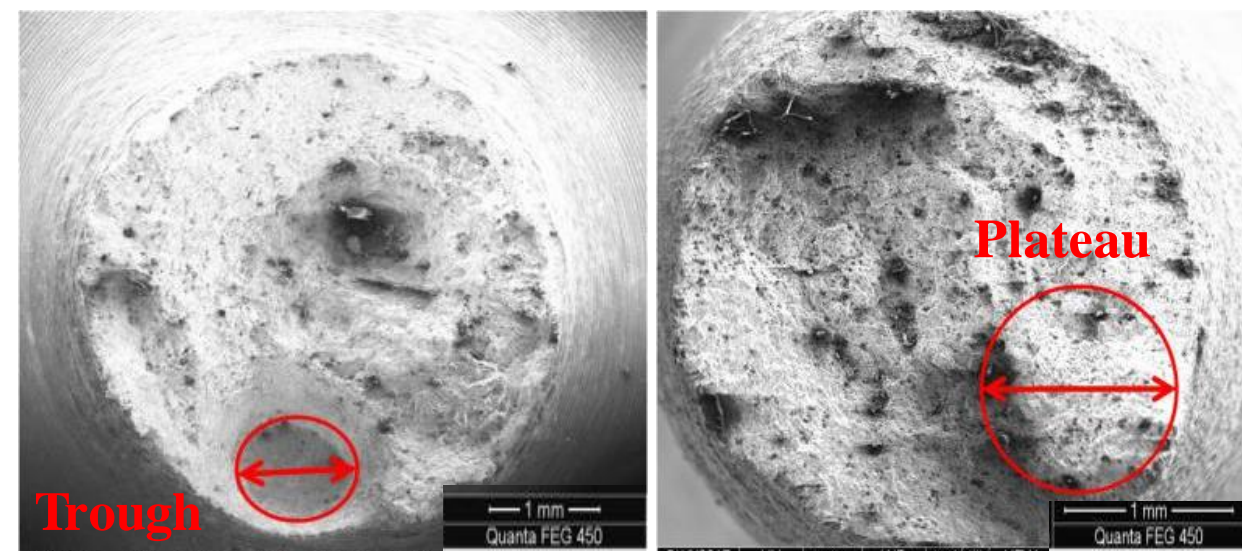

(a) Upper limit of characteristic length
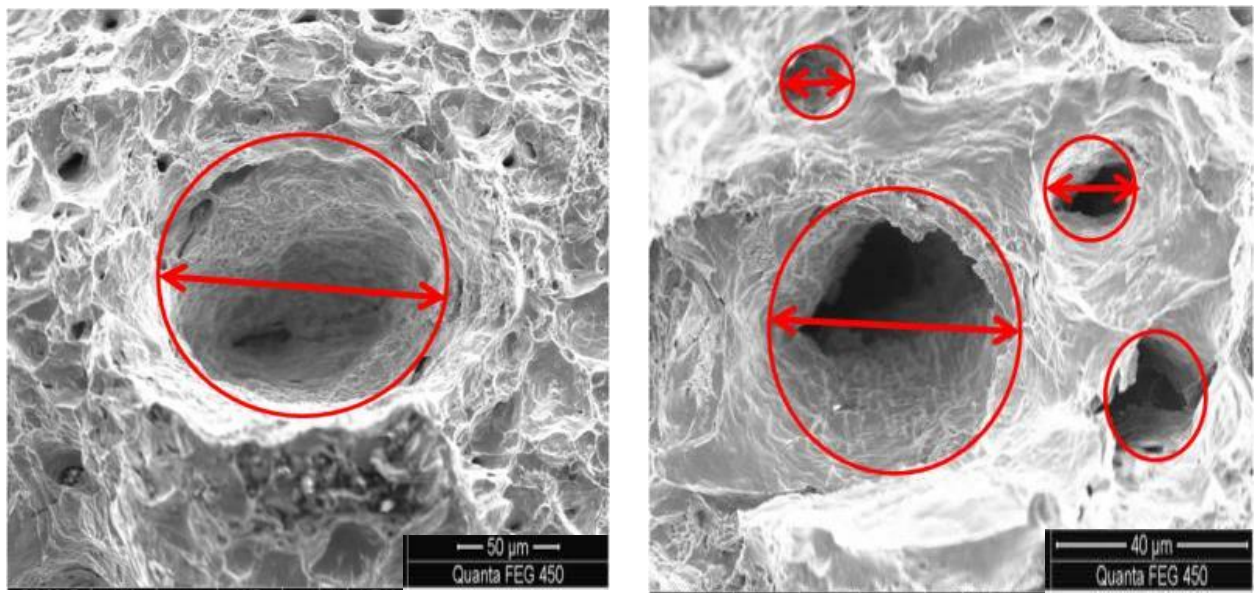

(b) Lower limit of characteristic length

Fig. 15 SEM measurements of typical fracture surfaces

Micromechanics-based model assumes crack initiation at coalescence of adjacent voids. The lower limit of the characteristic length is twice the diameter of the average dimple, while the upper limit is the size of the largest plateau or trough observed in the fractograph ${ }^{[23]}$. This method might bring scatters to the value of characteristic lengths, thus influencing the material toughness value. The mean value of the characteristic length is taken as the average of 10 measurements of the size of plateaus or troughs. The typical fracture surfaces are shown in Fig. 15. The upper limit, average value and lower limit of the characteristic length are tabulated in Table 8 . 
Table 8

Characteristic length obtained from SEM measurements ( $\mathrm{mm}$ )

\begin{tabular}{|c|c|c|c|c|}
\hline \multirow{2}{*}{ Material } & \multirow{2}{*}{ ID } & \multicolumn{3}{|c|}{ Characteristic length } \\
\hline & & Lower limit & Upper limit & Mean value \\
\hline \multirow{4}{*}{ Q235B base metal } & BSML-1 & 0.051 & 0.513 & 0.236 \\
\hline & BLML-2 & 0.075 & 0.886 & 0.230 \\
\hline & BMML-2 & 0.081 & 0.424 & 0.295 \\
\hline & Average & 0.069 & 0.608 & 0.254 \\
\hline \multirow{4}{*}{ Q235B weld metal } & WLML-2 & 0.054 & 0.325 & 0.187 \\
\hline & WLML-2 & 0.049 & 0.463 & 0.276 \\
\hline & WLML-2 & 0.035 & 0.428 & 0.228 \\
\hline & Average & 0.046 & 0.405 & 0.230 \\
\hline \multirow{4}{*}{ Q235B HAZ } & HSML-1 & 0.072 & 0.470 & 0.193 \\
\hline & HMML-1 & 0.027 & 0.215 & 0.191 \\
\hline & HMML-1 & 0.038 & 0.283 & 0.187 \\
\hline & Average & 0.046 & 0.323 & 0.190 \\
\hline \multirow{4}{*}{ Q345B base metal } & BLMH-2 & 0.041 & 0.804 & 0.590 \\
\hline & BMMH-1 & 0.034 & 0.585 & 0.160 \\
\hline & BSMH-2 & 0.052 & 0.753 & 0.482 \\
\hline & Average & 0.042 & 0.714 & 0.411 \\
\hline \multirow{4}{*}{ Q345B weld metal } & WSMH-2 & 0.068 & 0.385 & 0.297 \\
\hline & WMMH-2 & 0.042 & 0.519 & 0.222 \\
\hline & WLMH-1 & 0.075 & 0.397 & 0.174 \\
\hline & Average & 0.062 & 0.434 & 0.231 \\
\hline \multirow{4}{*}{ Q345B HAZ } & HMMH-1 & 0.045 & 0.502 & 0.148 \\
\hline & HLMH-2 & 0.047 & 0.452 & 0.241 \\
\hline & HSMH-1 & 0.036 & 0.428 & 0.122 \\
\hline & Average & 0.043 & 0.461 & 0.17 \\
\hline
\end{tabular}

\section{Calibration and validation of micromechanical fracture models}

\subsection{Finite element models}

Finite element models corresponding to the notched tensile test specimens were developed to calibrate the facture parameters. The general-propose finite element (FE) package ABAQUS was used. The gauge part of the specimen was simulated with axisymmetric 2-dimensional FE model with axisymmetry boundary conditions along the centre. One end of the gauge part was hinged while the other end was loaded with displacement control. The four-node axisymmetric element CAX4 from the ABAQUS element library was adopted. The geometries of the corresponding test specimens were employed, while the average material properties from the smooth round bar tensile coupon tests were used. Element size in the vicinity of the gap was taken around $0.2 \mathrm{~mm}$, with reference to the aforementioned average value of characteristic length $l^{*}$ obtained in the SEM measurements, as shown in Fig. 16. The fracture points obtained from the notched tensile tests, as shown in Fig. 13, were used for displacement control in the models. The load-displacement curves from the tests and FE models are compared in Figs. 17 and 18, for Q235B and Q345B respectively.

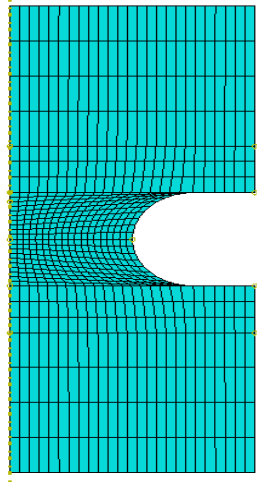

(a) $R=1.25 \mathrm{~mm}$

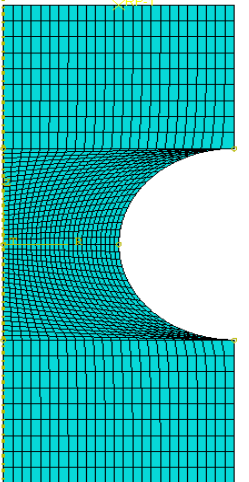

(b) $R=2.50 \mathrm{~mm}$

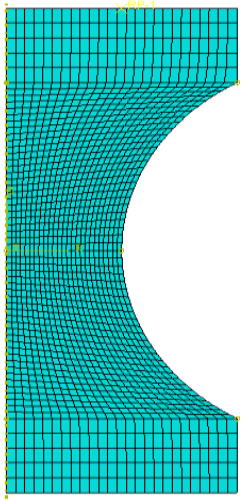

(c) $R=5.00 \mathrm{~mm}$

Fig. 16 Finite element model mesh 


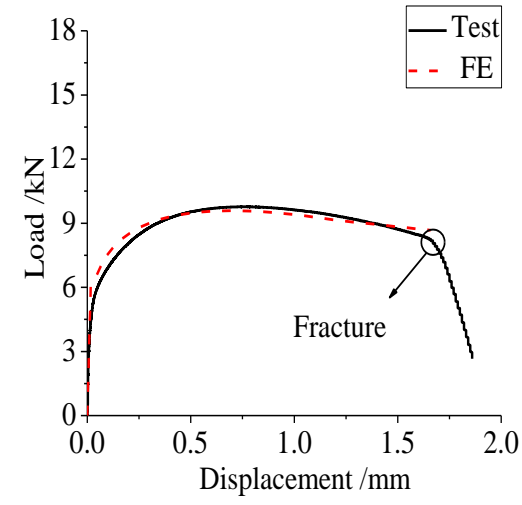

(a)BLML-1

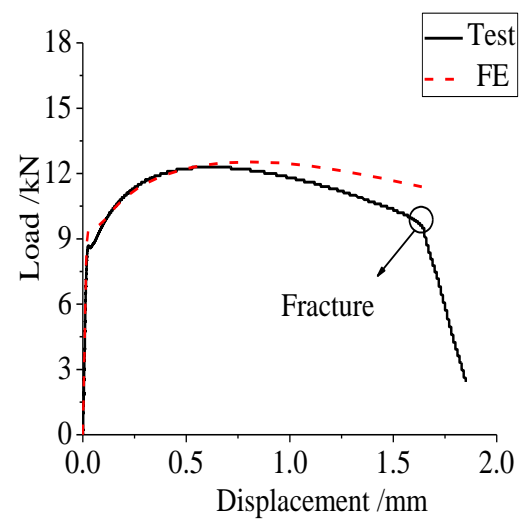

(d)WLML-1

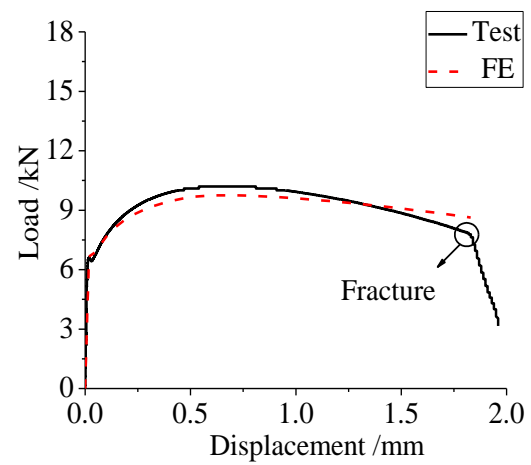

(g)HLML-1

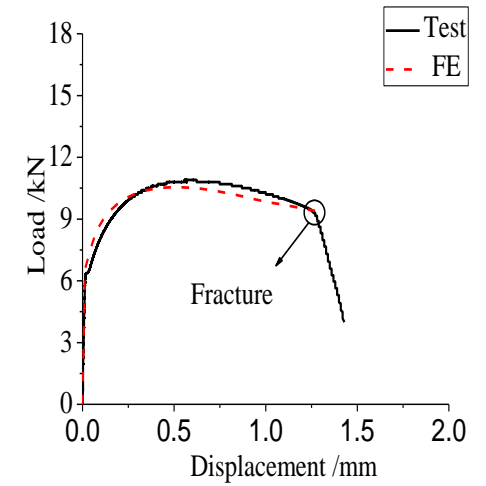

(b)BMML-1

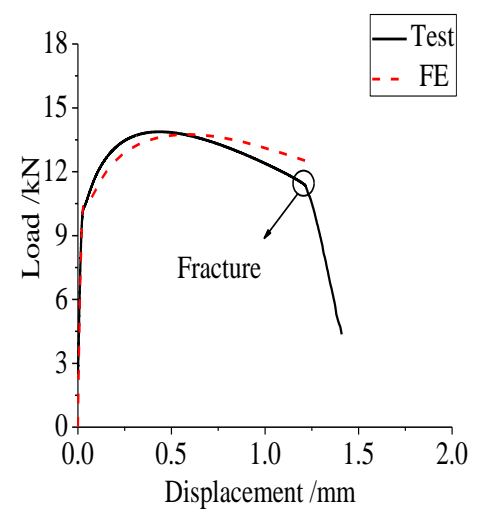

(e)WMML-1

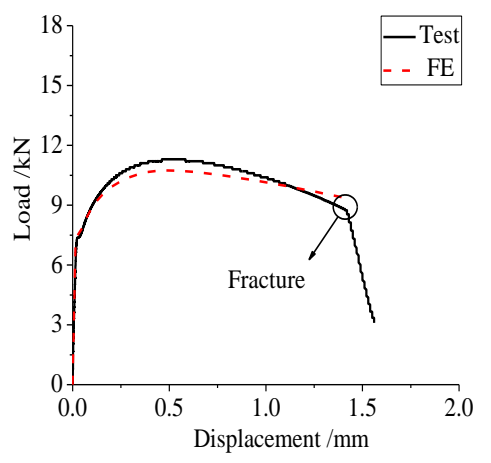

(h)HMML-1

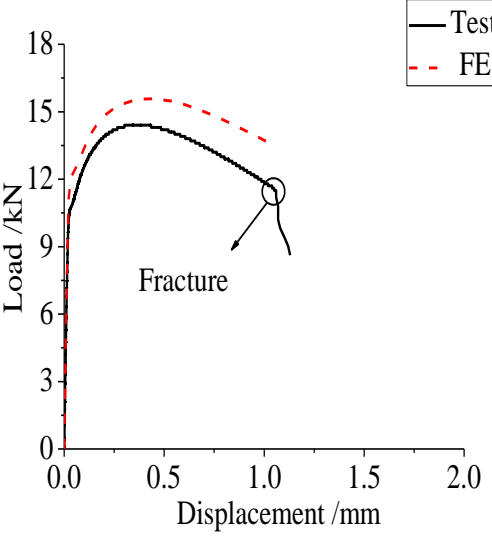

(f)WSML-1

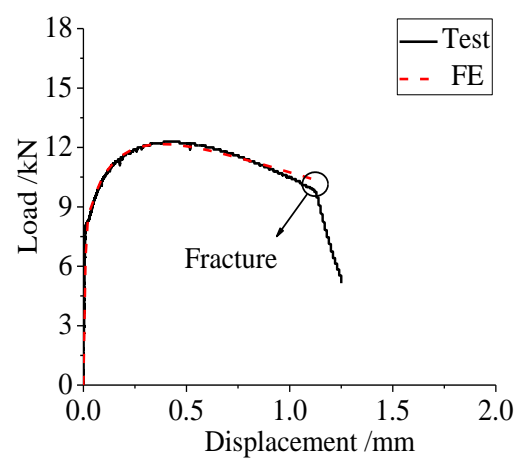

(i)HSML-1

Fig. 17 Load-displacement curves of Q235B

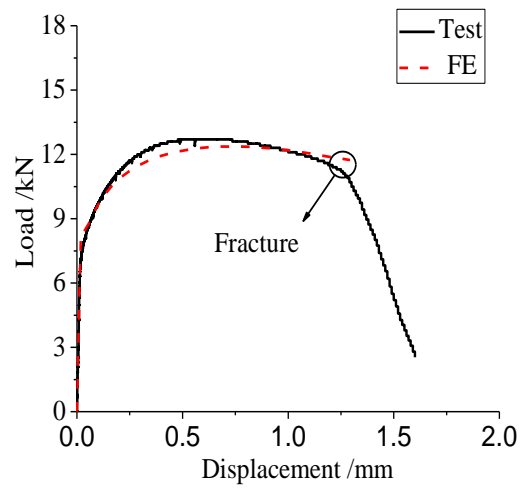

(a)BLMH-1

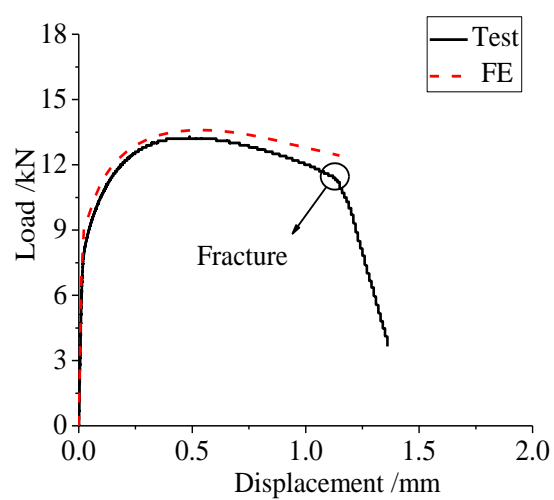

(b)BMMH-1

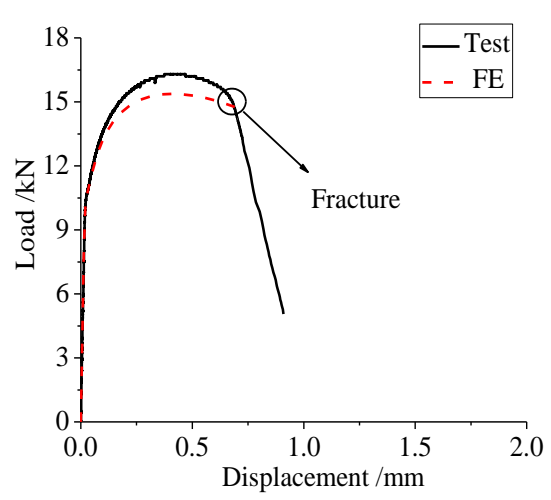

(c)BSMH-1 


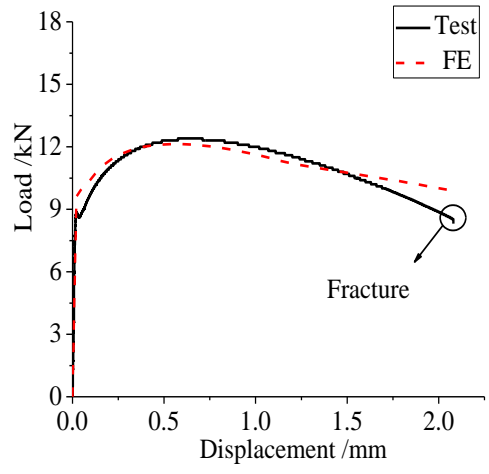

(c)WLMH-1

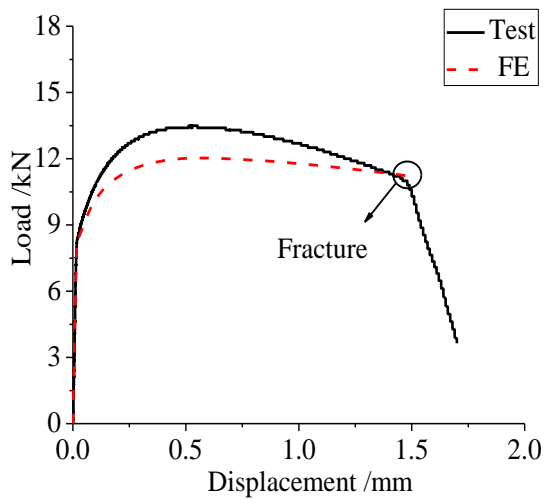

(f)HLMH-1

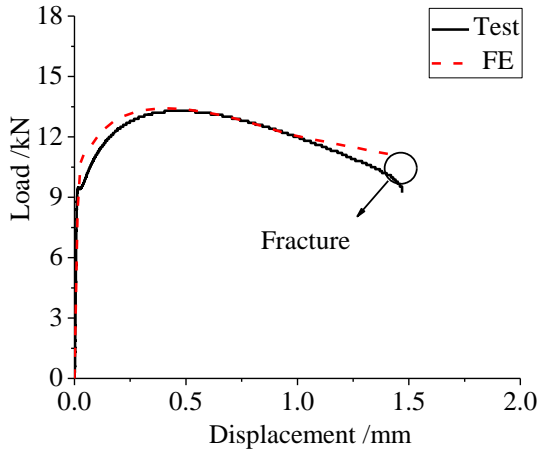

(d)WMMH-1

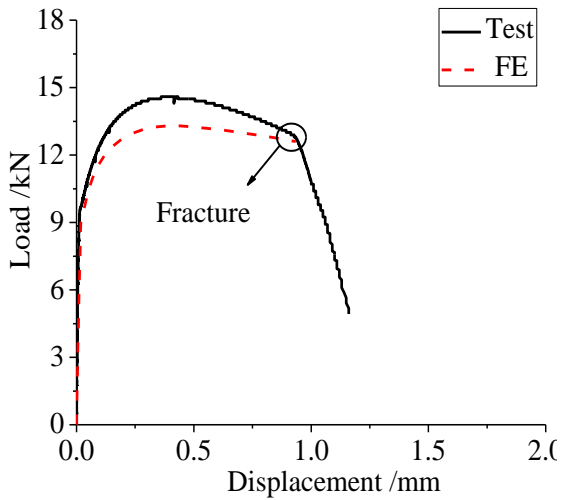

(g)HMMH-1

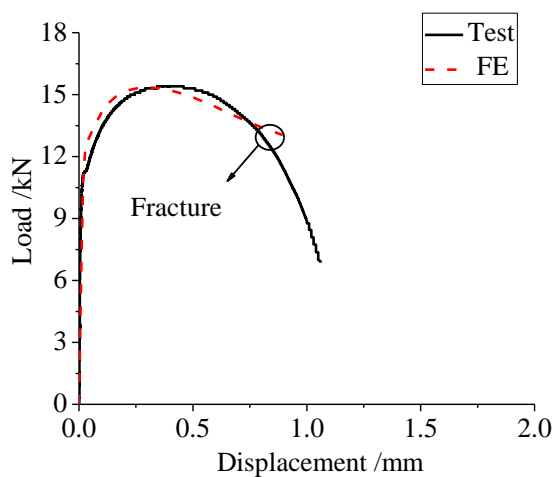

(e)WSMH-1

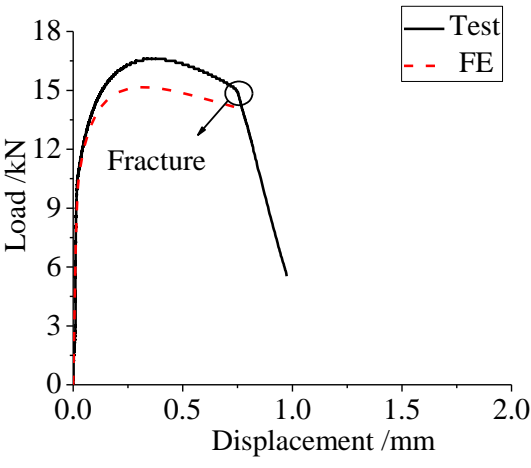

(h)HSMH-1

Fig. 18 Load-displacement curves of Q345B

\subsection{Toughness parameters calibration}

With fracture reaching the critical state, the toughness parameters $\eta_{\text {mon }}$ and $\gamma$, in VGM model and SMCS model respectively, were back-calculated through the UMAT subroutine in ABAQUS. The results at fracture displacement obtained from the finite element models are shown in Tables 9 and 10, where $\varepsilon_{\mathrm{p}, \mathrm{cr}}$ is plastic strain, ${ }^{\sigma_{m}}$ is von Mises stress, ${ }^{e}$ is equivalent stress, ${ }^{{ }_{f}}$ is fracture radius, $T$ is stress triaxiality. The results show that with increasing notch radius, the stress triaxiality $T$ decreases. It can be seen that the toughness parameters $\eta_{\text {mon }}$ and $\gamma$ of Q345B are less scatter than that of the Q235B. That may be caused by the better plasticity of Q235B than that of Q345B, and the equivalent plastic strain varies greatly with the stress triaxiality, showing higher level of microvoid expansion capacity. By comparing the toughness parameters of base material, weld metal and heat affected zone, the values of heat affected zone are relative small, while the average values of these three materials are close, which indicates that the calibrated parameters can be used to predict fracture initiation in welded steel components under different stress state.

Table 9

Calibrations for toughness parameters of Q235B

\begin{tabular}{|c|c|c|c|c|c|c|c|c|c|c|}
\hline Material & $R / \mathrm{mm}$ & ID & $\delta_{\mathrm{f}} / \mathrm{mm}$ & $\varepsilon_{\mathrm{p}, \mathrm{cr}}$ & $\sigma_{\mathrm{m}} / \mathrm{MPa}$ & $d_{\mathrm{f}} / d_{0}$ & $\sigma_{\mathrm{e}} / \mathrm{MPa}$ & $T$ & $\gamma$ & $\eta_{\text {mon }}$ \\
\hline \multirow{6}{*}{$\begin{array}{l}\text { Base } \\
\text { metal }\end{array}$} & \multirow{2}{*}{1.25} & BSML-1 & 1.08 & 0.783 & 680.6 & 0.768 & 768.1 & 0.886 & 2.665 & 2.712 \\
\hline & & BSML-2 & 0.94 & 0.673 & 687.4 & 0.762 & 708.5 & 0.970 & 2.531 & 2.637 \\
\hline & \multirow{2}{*}{2.50} & BMML-1 & 1.27 & 0.637 & 560.2 & 0.756 & 688.8 & 0.813 & 2.094 & 2.311 \\
\hline & & BMML-2 & 1.40 & 0.714 & 564.6 & 0.759 & 730.4 & 0.773 & 2.205 & 2.546 \\
\hline & \multirow{2}{*}{5.00} & BLML-1 & 1.66 & 0.658 & 473.7 & 0.699 & 699.7 & 0.677 & 1.815 & 1.911 \\
\hline & & BLML-2 & 1.65 & 0.653 & 473.0 & 0.722 & 697.3 & 0.678 & 1.807 & 1.899 \\
\hline \multicolumn{9}{|c|}{ Mean value } & 2.186 & 2.408 \\
\hline \multicolumn{9}{|c|}{$\mathrm{COV}$} & 0.16 & 0.15 \\
\hline \multirow{6}{*}{$\begin{array}{l}\text { Weld } \\
\text { metal }\end{array}$} & \multirow{2}{*}{1.25} & WSML-1 & 1.06 & 0.789 & 914.30 & 0.748 & 985.0 & 0.928 & 2.626 & 2.924 \\
\hline & & WSML-2 & 1.03 & 0.765 & 908.93 & 0.697 & 971.8 & 0.935 & 2.555 & 2.827 \\
\hline & \multirow{2}{*}{2.50} & WMML-1 & 1.22 & 0.600 & 741.77 & 0.694 & 881.8 & 0.841 & 1.966 & 1.981 \\
\hline & & WMML-2 & 1.04 & 0.503 & 700.47 & 0.711 & 829.5 & 0.844 & 1.631 & 1.648 \\
\hline & \multirow{2}{*}{5.00} & WLML-1 & 1.65 & 0.621 & 646.80 & 0.665 & 893.0 & 0.724 & 1.834 & 1.745 \\
\hline & & WLML-2 & 1.89 & 0.751 & 714.13 & 0.621 & 967.3 & 0.738 & 2.272 & 2.169 \\
\hline \multicolumn{9}{|c|}{ Mean value } & 2.147 & 2.216 \\
\hline \multicolumn{9}{|c|}{$\mathrm{COV}$} & 0.19 & 0.25 \\
\hline \multirow{2}{*}{ HAZ } & \multirow{2}{*}{1.25} & HSML-1 & 1.13 & 0.845 & 715.3 & 0.735 & 802.9 & 0.891 & 2.683 & 3.609 \\
\hline & & HSML-2 & 1.06 & 0.785 & 707.6 & 0.703 & 775.4 & 0.913 & 2.697 & 3.406 \\
\hline
\end{tabular}




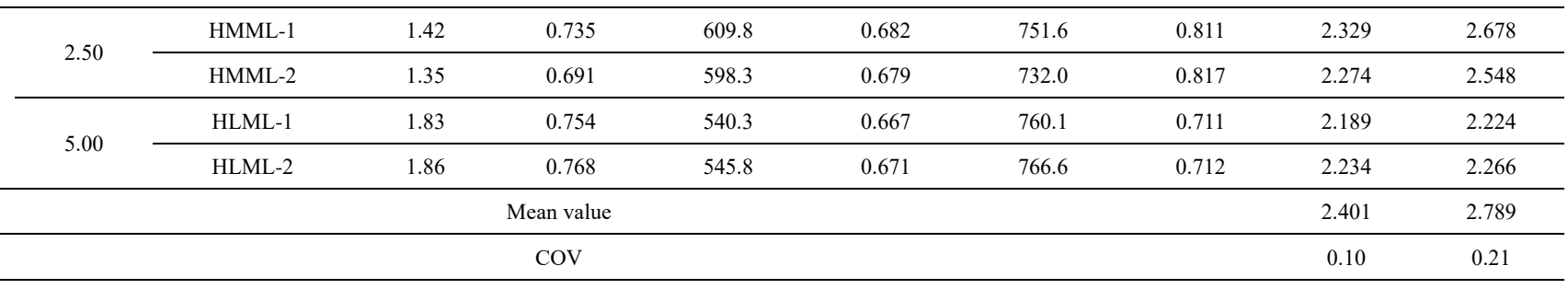

\section{Table 10}

Calibrations for toughness parameters of Q345B

\begin{tabular}{|c|c|c|c|c|c|c|c|c|c|c|}
\hline Material & $R / \mathrm{mm}$ & ID & $\delta_{\mathrm{f}} / \mathrm{mm}$ & $\varepsilon_{\mathrm{p}, \mathrm{cr}}$ & $\sigma_{\mathrm{m}} / \mathrm{MPa}$ & $d_{\mathrm{f}} / d_{0}$ & $\sigma_{\mathrm{e}} / \mathrm{MPa}$ & $T$ & $\gamma$ & $\eta_{\text {mon }}$ \\
\hline \multirow{8}{*}{$\begin{array}{l}\text { Base } \\
\text { metal }\end{array}$} & \multirow{2}{*}{1.25} & BSMH-1 & 0.69 & 0.491 & 850.7 & 0.820 & 761.1 & 1.118 & 2.039 & 2.070 \\
\hline & & BSMH-2 & 0.8 & 0.572 & 873.63 & 0.760 & 813.8 & 1.074 & 2.451 & 2.515 \\
\hline & \multirow{2}{*}{2.50} & BMMH-1 & 1.15 & 0.577 & 697.03 & 0.730 & 816.8 & 0.853 & 2.085 & 2.287 \\
\hline & & BMMH-2 & 1.22 & 0.618 & 708.37 & 0.700 & 843.4 & 0.84 & 2.138 & 2.427 \\
\hline & \multirow{2}{*}{5.00} & BLMH-1 & 1.29 & 0.520 & 583.33 & 0.730 & 779.4 & 0.748 & 1.597 & 1.581 \\
\hline & & BLMH-2 & 1.79 & 0.749 & 623.7 & 0.730 & 929.2 & 0.671 & 2.049 & 2.236 \\
\hline & \multicolumn{8}{|c|}{ Mean value } & 2.060 & 2.186 \\
\hline & \multicolumn{8}{|c|}{$\mathrm{COV}$} & 0.13 & 0.15 \\
\hline \multirow{8}{*}{ Weld metal } & \multirow{2}{*}{1.25} & WSMH-1 & 0.894 & 0.685 & 875.8 & 0.756 & 827.2 & 1.059 & 3.056 & 3.445 \\
\hline & & WSMH-2 & 0.895 & 0.686 & 875.67 & 0.787 & 827.7 & 1.058 & 3.057 & 3.309 \\
\hline & \multirow{2}{*}{2.50} & WMMH-1 & 1.152 & 0.600 & 714.67 & 0.563 & 780.3 & 0.916 & 2.343 & 2.520 \\
\hline & & WMMH-2 & 1.42 & 0.768 & 732.1 & 0.548 & 871.3 & 0.83 & 2.671 & 3.105 \\
\hline & \multirow{2}{*}{5.00} & WLMH-1 & 2.079 & 0.944 & 698.97 & 0.578 & 965.4 & 0.724 & 2.796 & 2.919 \\
\hline & & WLMH-2 & 2.100 & 0.955 & 703.87 & 0.601 & 971.3 & 0.725 & 2.831 & 2.951 \\
\hline & \multicolumn{8}{|c|}{ Mean value } & 2.792 & 3.042 \\
\hline & \multicolumn{8}{|c|}{$\mathrm{COV}$} & 0.10 & 0.11 \\
\hline \multirow{8}{*}{ HAZ } & \multirow{2}{*}{1.25} & HSMH-1 & 0.748 & 0.522 & 924.87 & 0.769 & 828.6 & 1.116 & 2.263 & 2.298 \\
\hline & & HSMH-2 & 0.745 & 0.520 & 924.27 & 0.770 & 827.3 & 1.117 & 2.251 & 2.284 \\
\hline & \multirow{2}{*}{2.50} & НММН-1 & 1.000 & 0.483 & 751.13 & 0.730 & 805.8 & 0.932 & 1.913 & 1.938 \\
\hline & & HMMH-2 & 0.936 & 0.447 & 748.1 & 0.740 & 785.1 & 0.953 & 1.812 & 1.785 \\
\hline & \multirow{2}{*}{5.00} & HLMH-1 & 1.500 & 0.62 & 648.33 & 0.674 & 884.3 & 0.733 & 1.860 & 1.898 \\
\hline & & HLMH-2 & 1.480 & 0.61 & 645.47 & 0.685 & 878.8 & 0.734 & 1.836 & 1.869 \\
\hline & \multicolumn{8}{|c|}{ Mean value } & 1.989 & 2.012 \\
\hline & \multicolumn{8}{|c|}{$\mathrm{COV}$} & 0.11 & 0.11 \\
\hline
\end{tabular}

\subsection{Discussions}

Having calibrated the toughness parameters of the two models, numerical results were compared and discussed.

The von Mises stress field, triaxiality stress field and the equivalent plastic strain field of a typical group of specimens (Q345B base metal specimens with different notch sizes) are shown in Fig. 19. Specimens with different notch sizes shows different stress and strain fields.

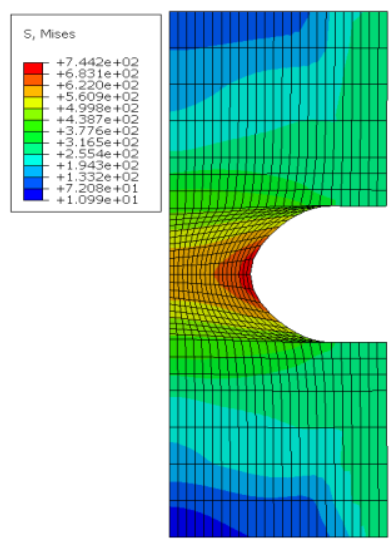

von Mises stress

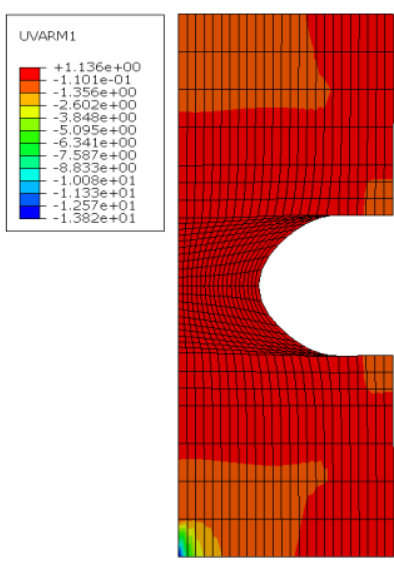

Stress triaxiality

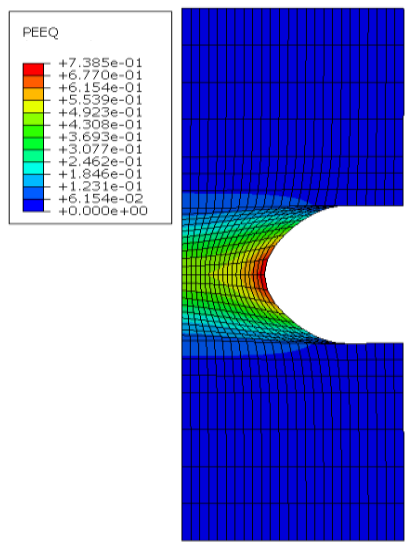

Equivalent plastic strain

(a) $R=1.25 \mathrm{~mm}$ 


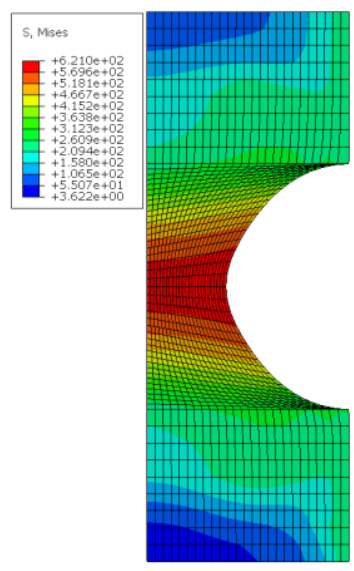

von Mises stress

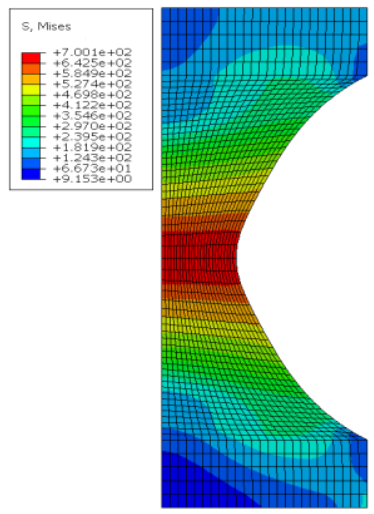

von Mises stress

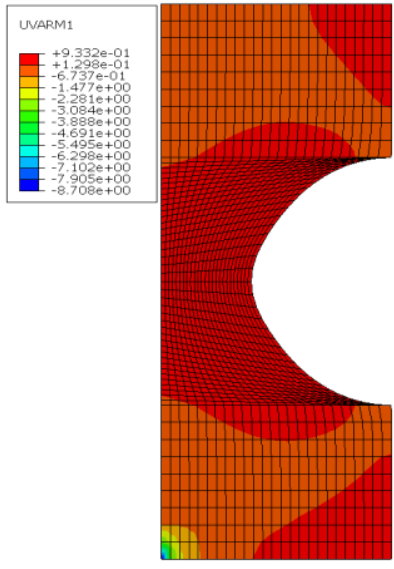

Stress triaxiality

(b) $R=2.50 \mathrm{~mm}$

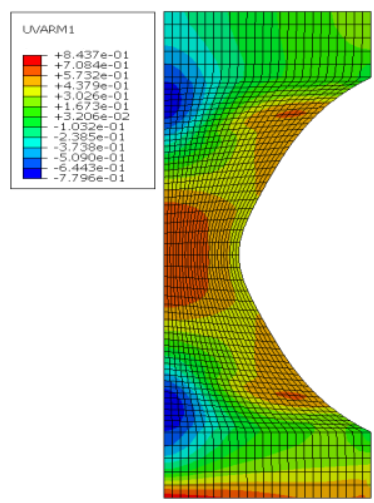

Stress triaxiality

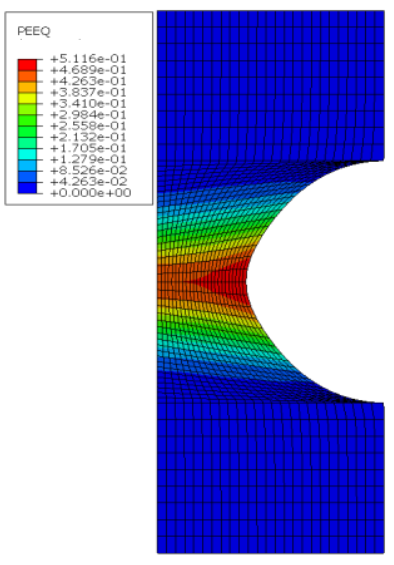

Equivalent plastic strain

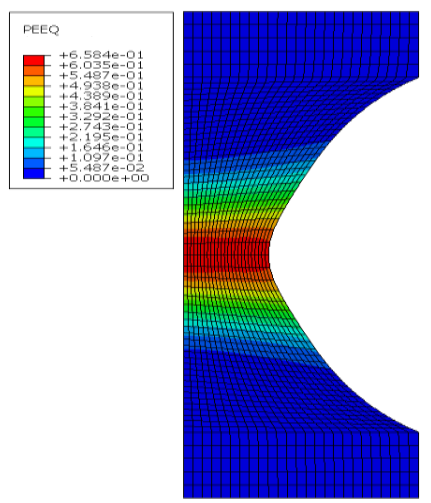

Equivalent plastic strain

(c) $R=5.00 \mathrm{~mm}$

Fig. 19 Distribution of stress and strain fields in notched area

The equivalent plastic strain and triaxial stress distribution along the notched cross-section at crack initiation is shown in Figs. 20 and 21, respectively. PEEQ is the value of equivalent plastic strain while UVARM1 is the stress triaxiality, output from the subroutine in ABAQUA. It can be observed that for round bars with a notch radius of $R=5.00 \mathrm{~mm}$, the equivalent plastic strain is distributed uniformly along the notched section. With smaller notch radius of $R=2.50 \mathrm{~mm}$ and $1.25 \mathrm{~mm}$, the equivalent plastic strain is high at the edge and low near the centre. The maximum UVARM1 value, namely stress triaxiality, appears at the centre of the test piece, unlike the equivalent plastic strain distribution. Therefore, the fracture of materials, especially those in triaxial stress state, cannot be predicted with only equivalent plastic strain. The micromechanical fracture models take into consideration of the influence of both stress triaxiality and equivalent plastic strain, thus giving better predictions.

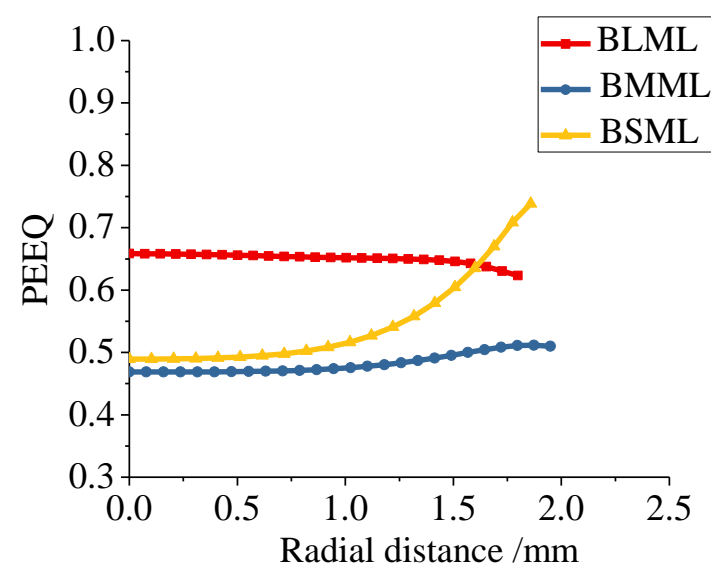

(a) Q235B base metal

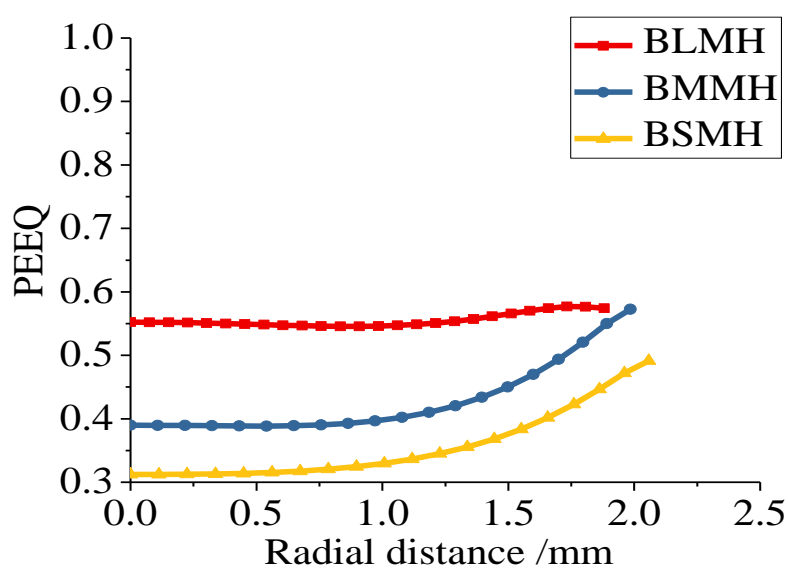

(b) Q345B base metal 


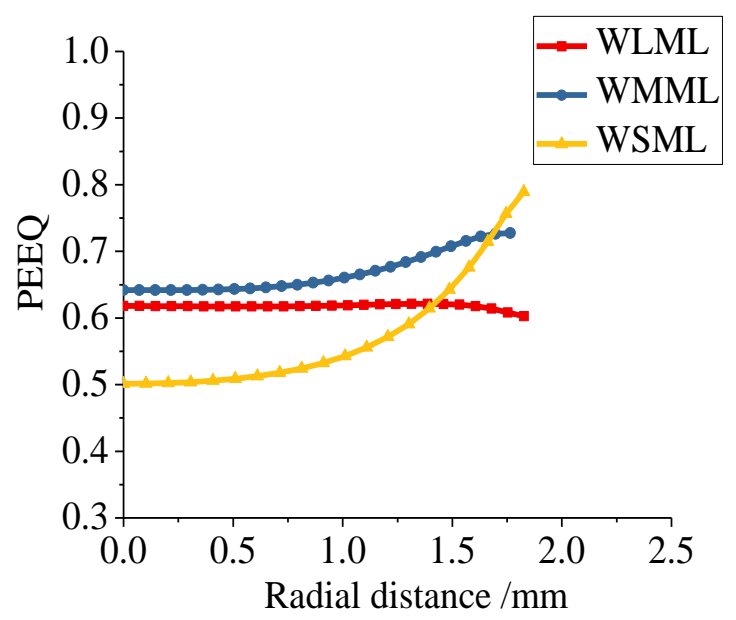

(c) Q235B weld metal

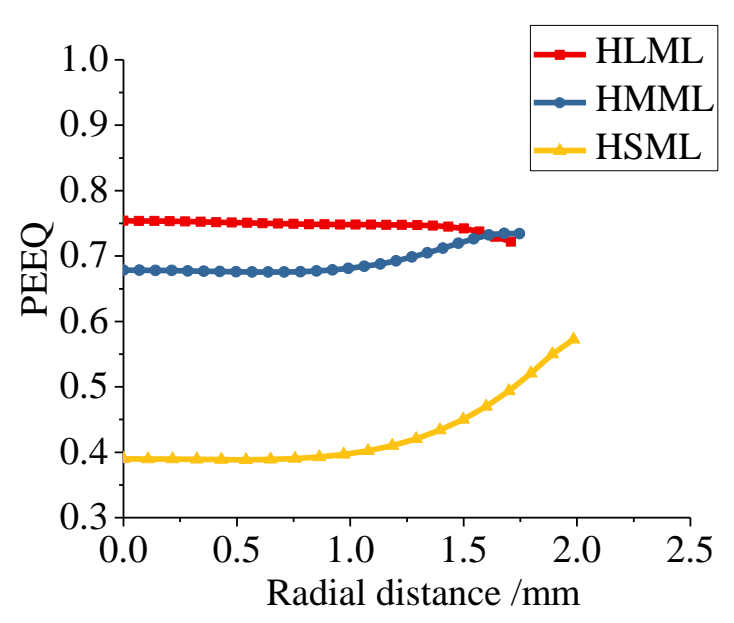

(e) Q235B HAZ

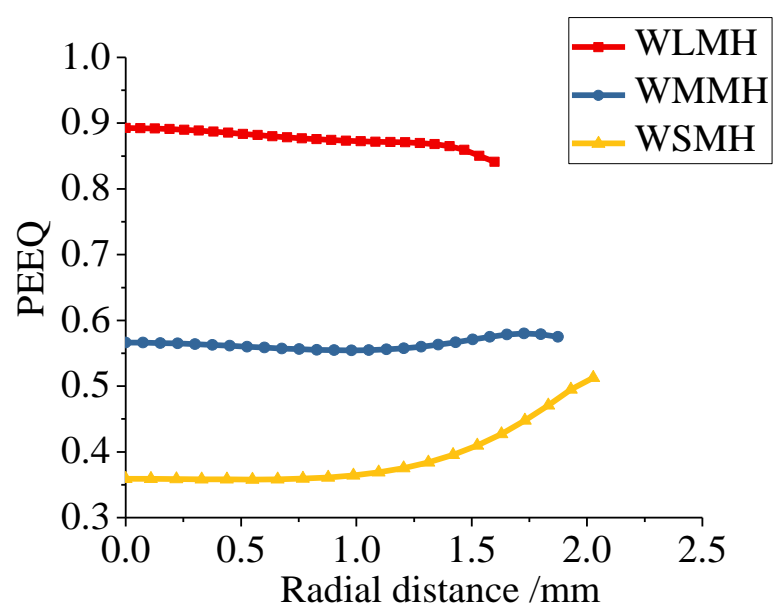

(d) Q345B weld metal

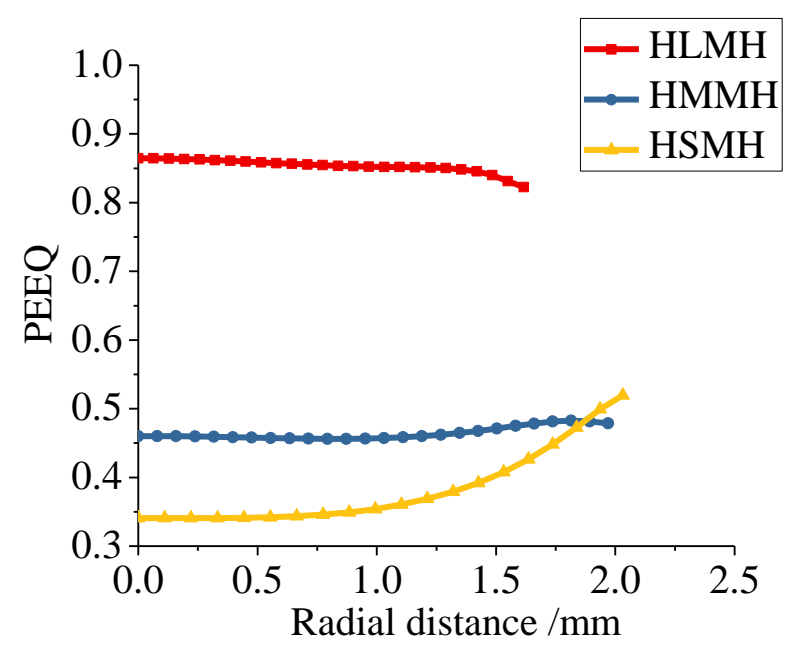

(f) Q345B HAZ

Fig. 20 Equivalent plastic strain of Q235B and Q345B

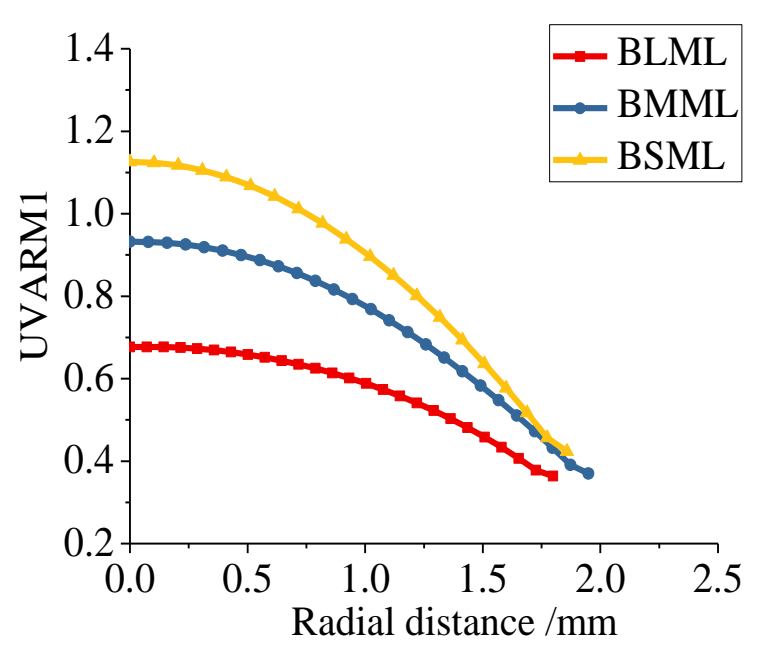

(a) Q235B base metal

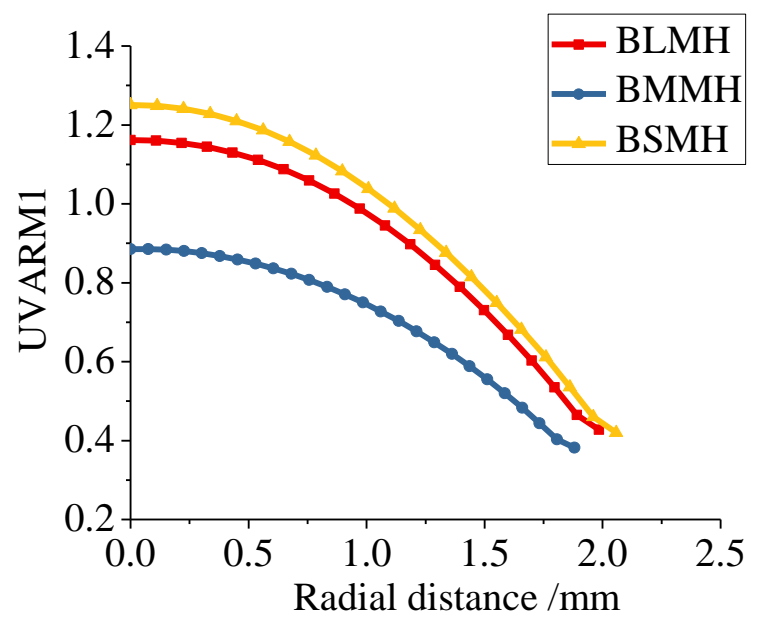

(b) Q345B base metal 


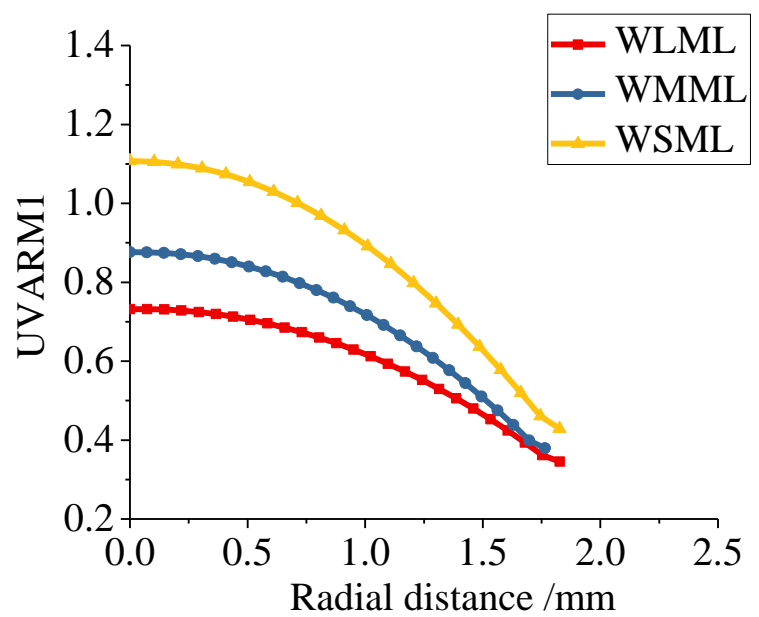

(c) Q235B weld metal

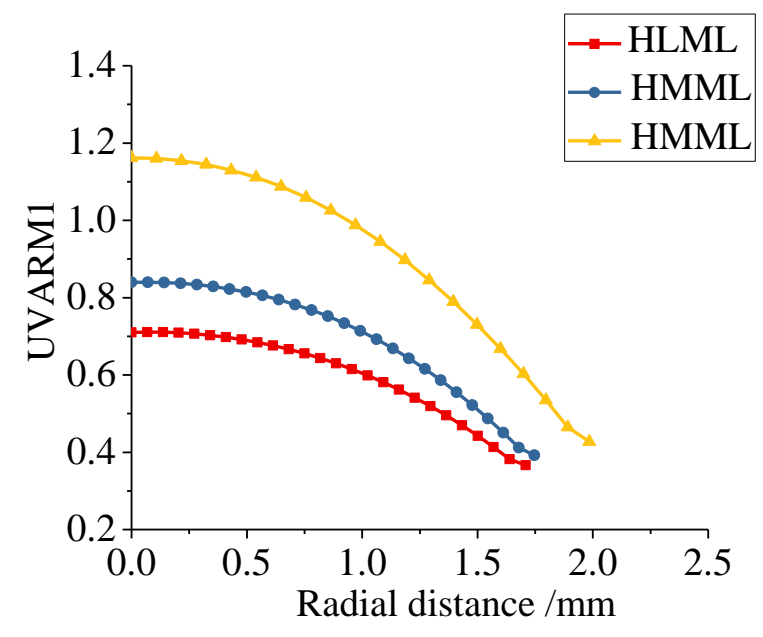

(e) Q235B HAZ

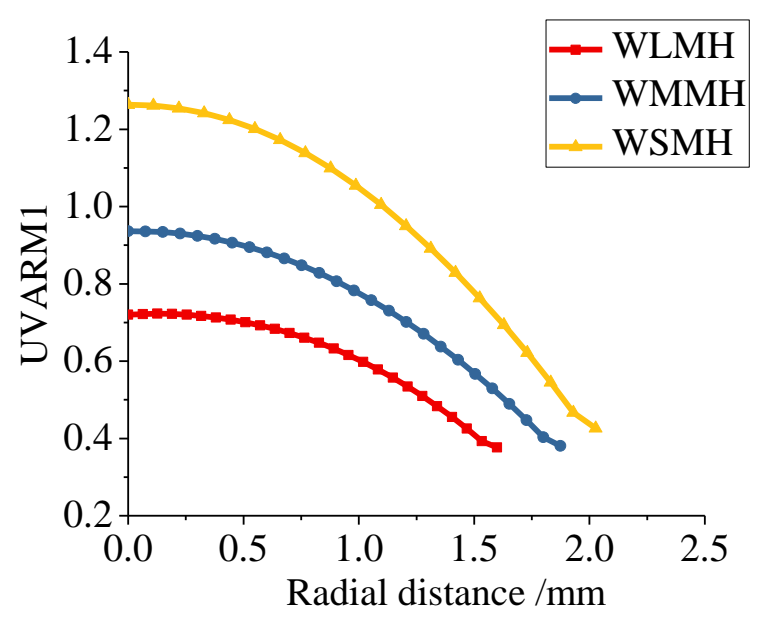

(d) Q345B weld metal

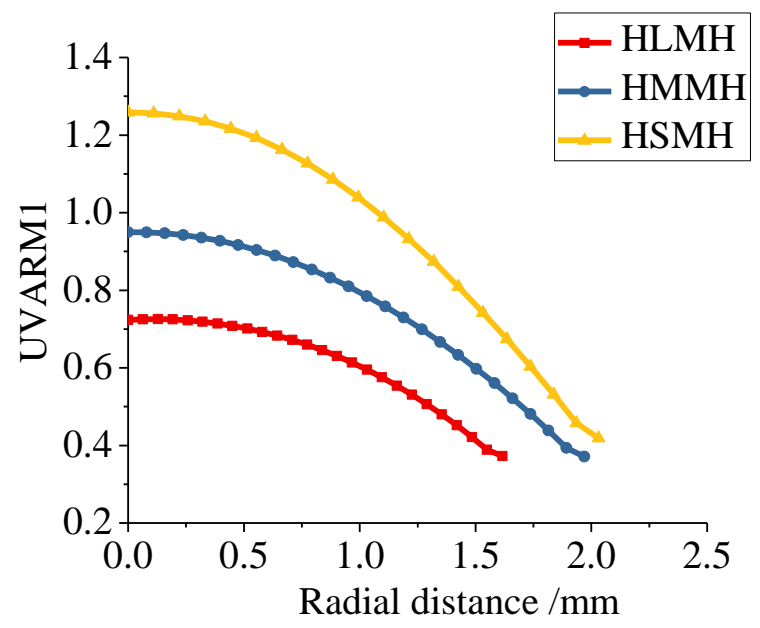

(f) Q345B HAZ

Fig. 21 UVARM1 of Q235B and Q345B

Figs. 22 and 23 show the VGM and SMCS fracture index, $\mathrm{FI}_{\mathrm{VGM}}$ and $\mathrm{FI}_{\mathrm{SMCS}}$ respectively, distribution along the notched cross-section at the fracture initiation (when fracture displacement is reached in the numerical model). It can be seen that the fracture index is biggest at the centre of the bar, indicating that the fracture initiates from the centre. This is consistent with the observations from the SEM measurements. For the three different stress states, the fracture parameters of the SMCS model and the VGM model show similar distributions along the notched cross-section: decreasing from the centre to the edge, having less change within a certain range. This also shows that for the notched round bar specimen, the value of the characteristic length based on the microstructure of the material has little effect on the fracture prediction, and there is no obvious correlation between the characteristic length and the value of the toughness parameters. The consistency in the distribution of fracture parameters in VGM and SMCS also shows that both models offer similar predictions under different stress states.

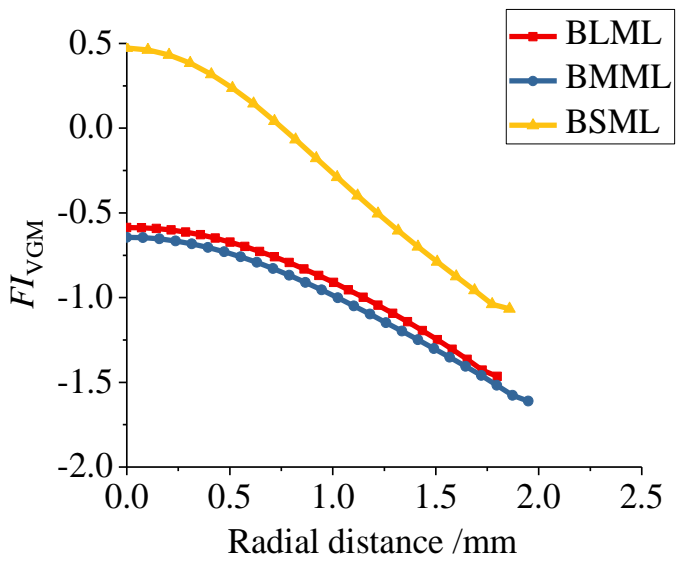

(a) Q235B base metal

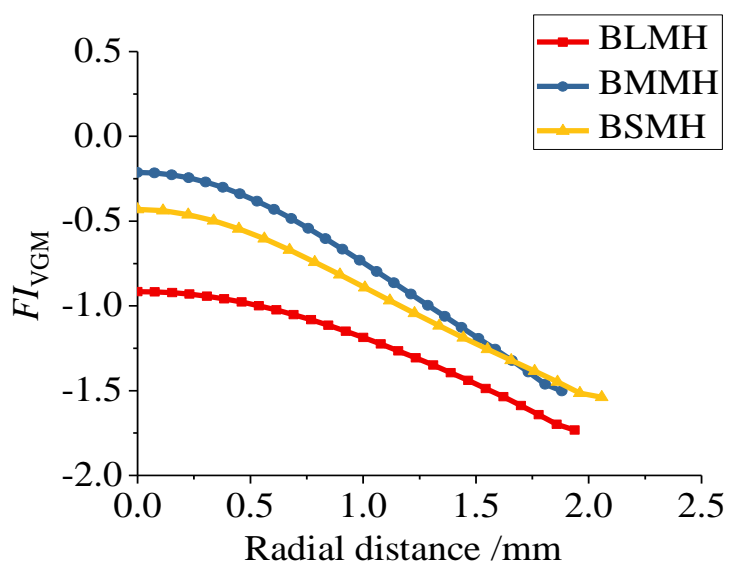

(b) Q345B base metal 


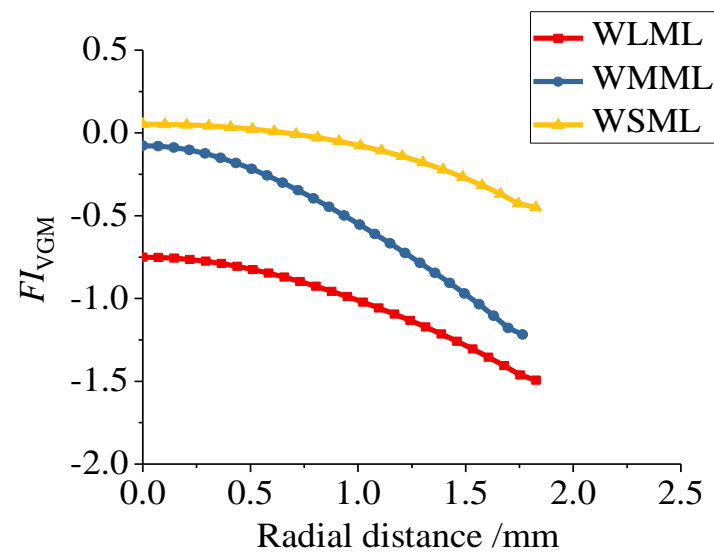

(c) Q235B weld metal

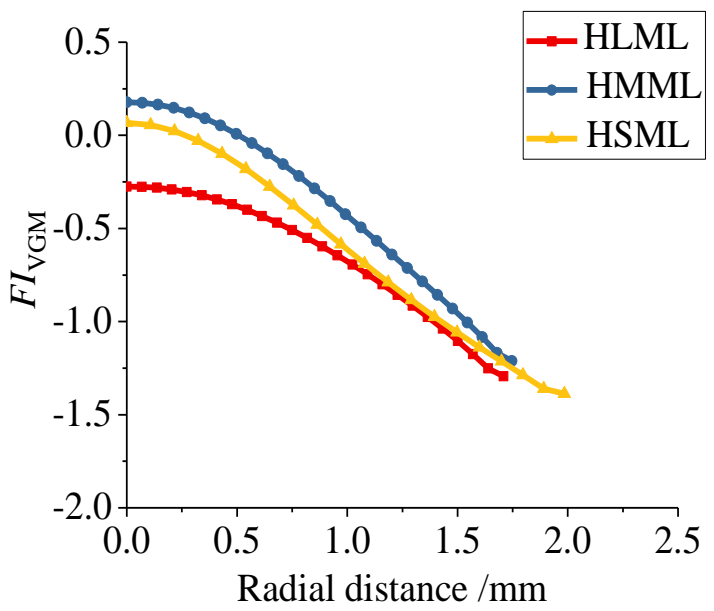

(e) Q235B HAZ

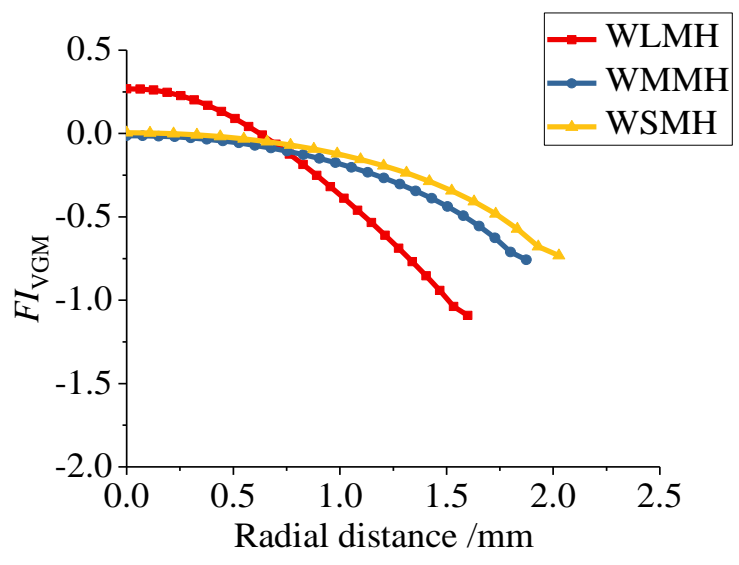

(d) Q345B weld metal

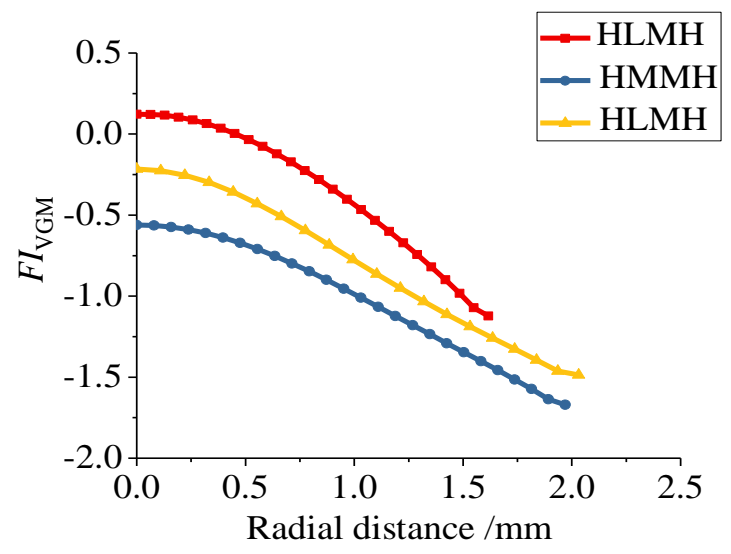

(f) Q235B HAZ

Fig. 22 Distribution of SMCS fracture index

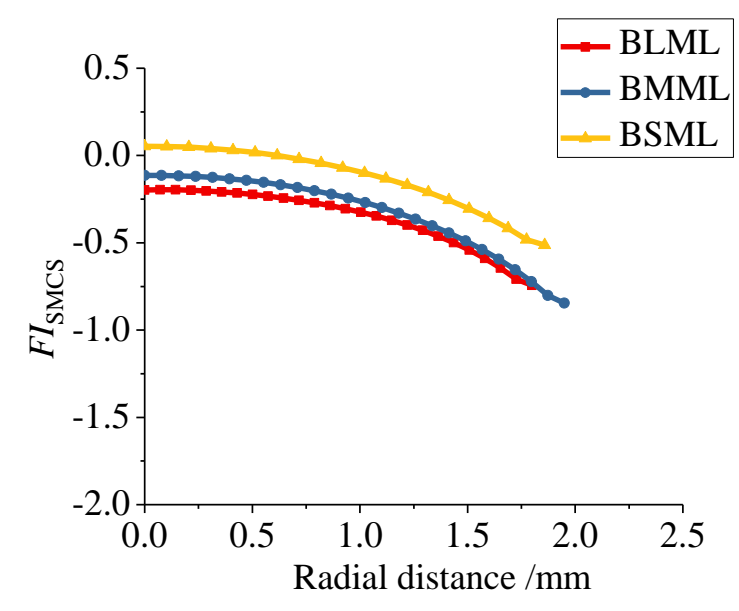

(a)Q235B base metal

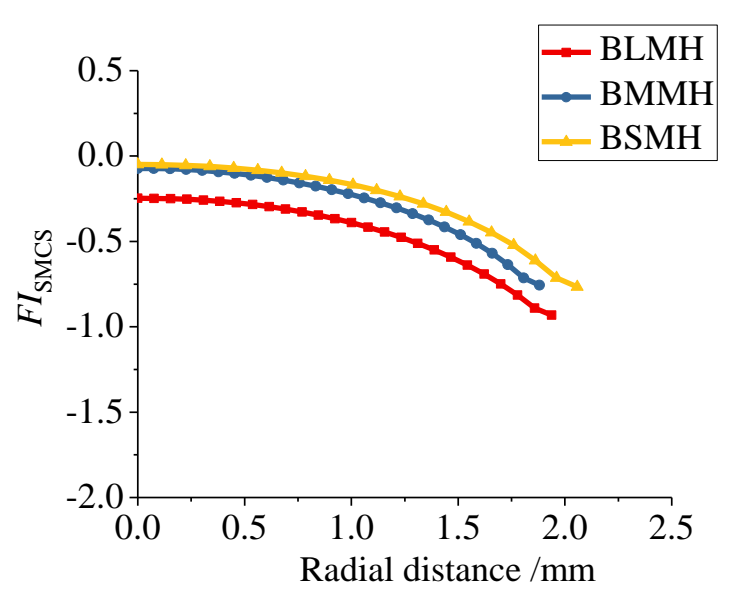

(b)Q345B base metal 


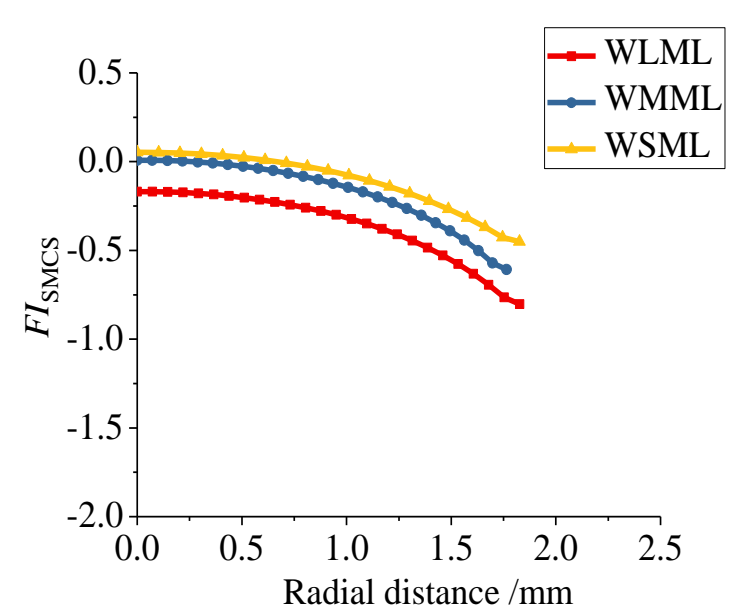

(c) Q235B weld metal

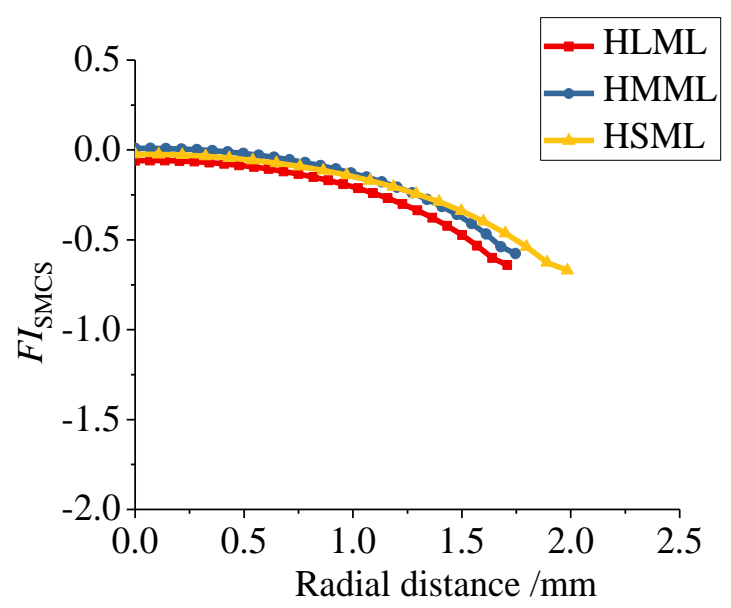

(e) Q235B HAZ

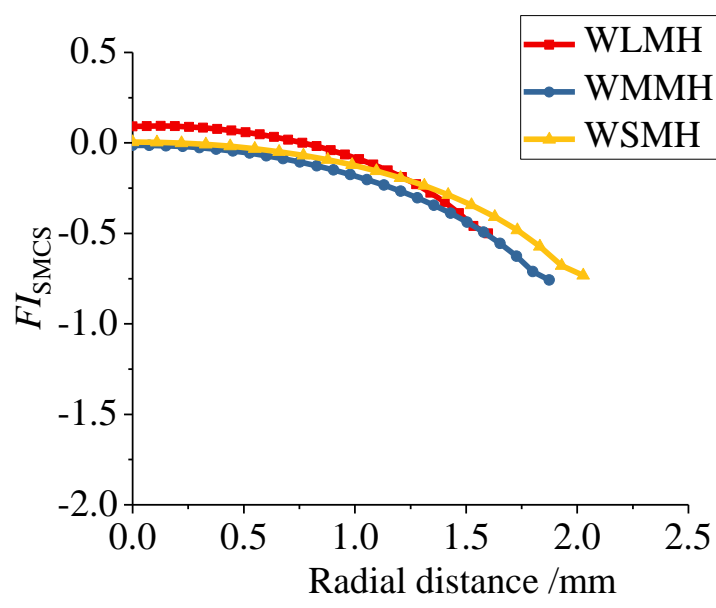

(d) Q345B weld metal

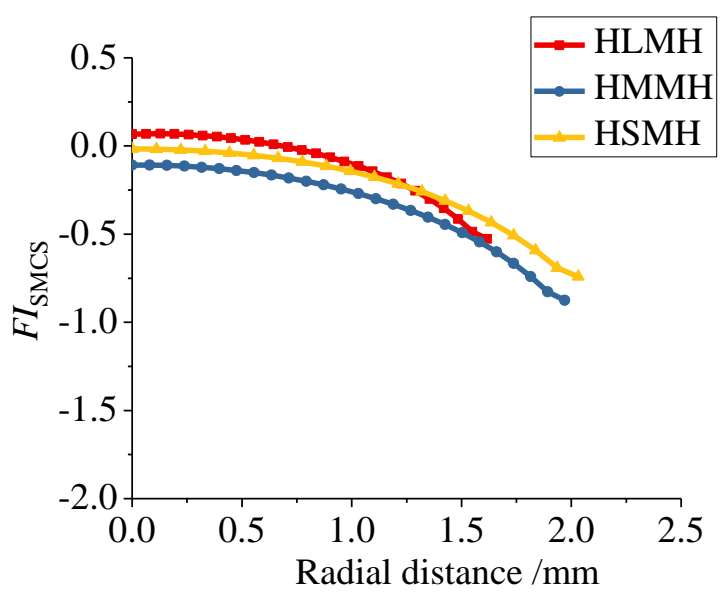

(f) Q345B HAZ

Fig. 23 Distribution of SMCS fracture index

\subsection{Fracture prediction}

With the calibrated toughness parameters, as listed in Tables 9 and 10 , the load-displacement response of monotonic experiments can be predicted with the VUMAT subroutine in ABAQUS. The comparisons of load-displacement curves are shown in Figs. 24 to 26 . Note that the FE curves are without subroutine and displacement controlled till the fracture displacement obtained in the tests. The fracture load and displacement obtained by tests are compared with the predictions in Tables 11 and 12, respectively. The fracture load and displacement predictions are compared with test results in Figs. 27 and 28, respectively. The typical test curves from each set of two repetitive specimens were employed.

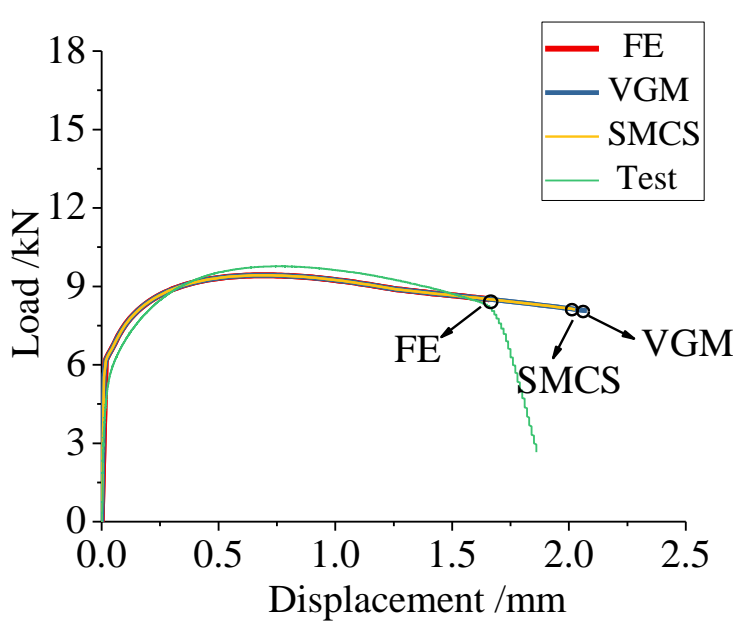

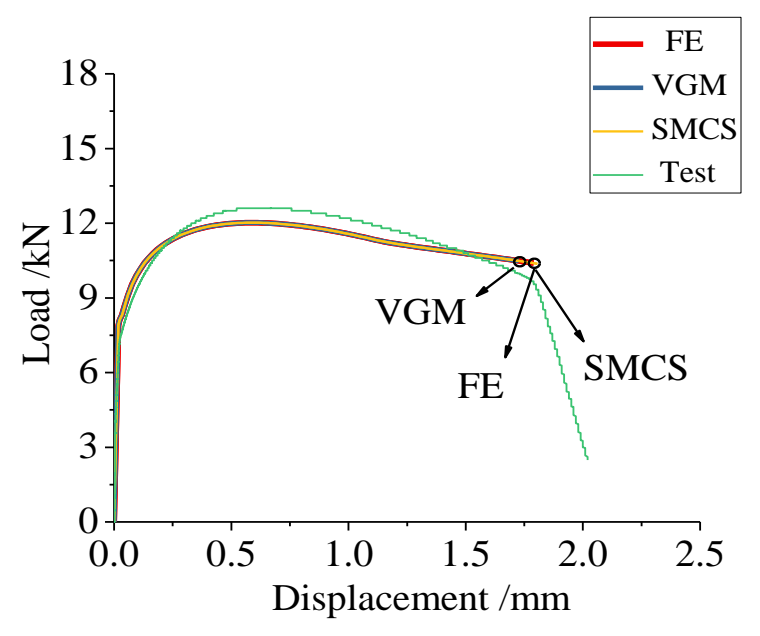

(b)BLMH 


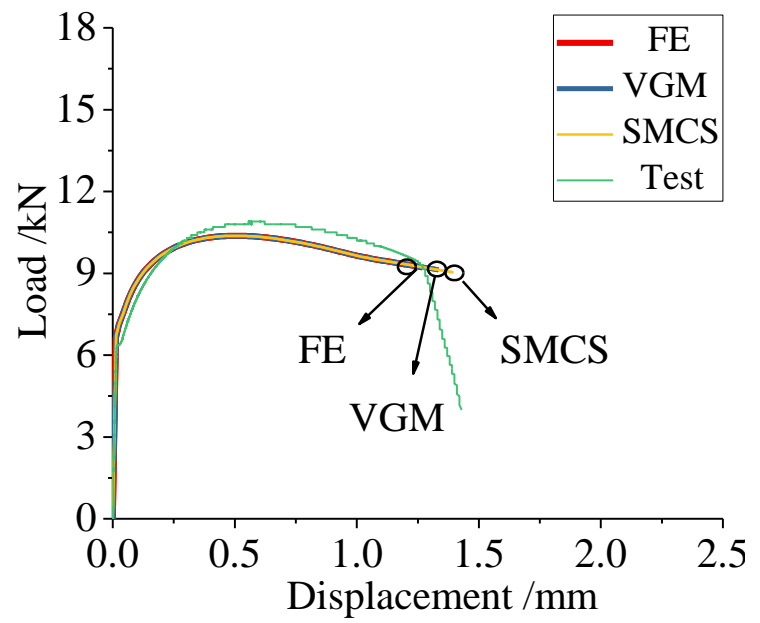

(c)BMML

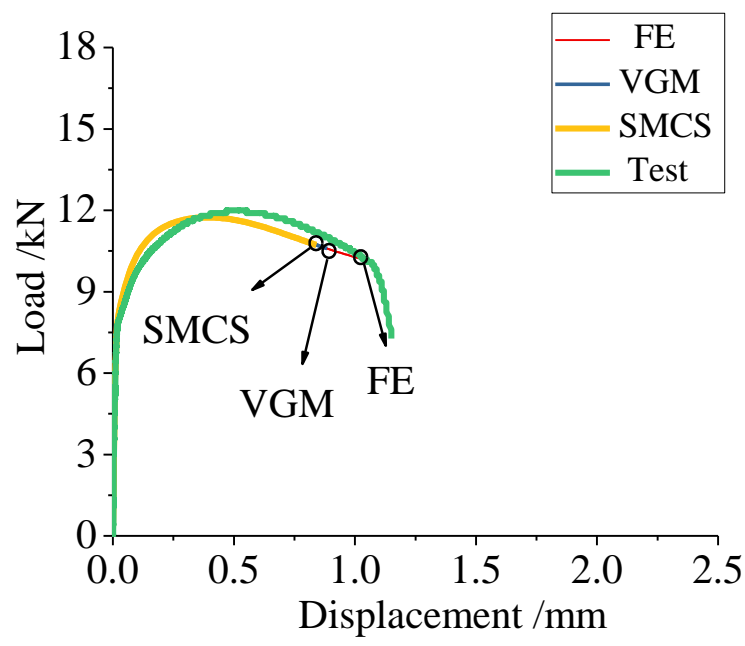

(e)BSML

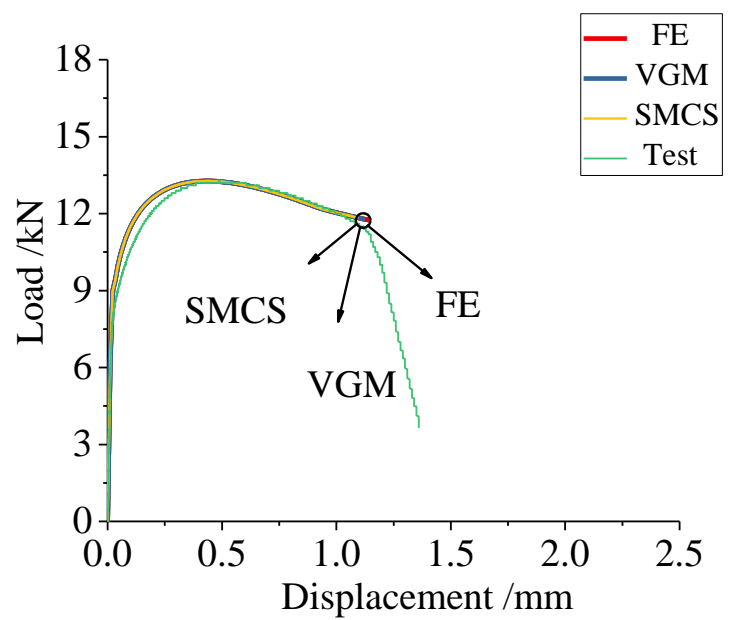

(d)BMMH

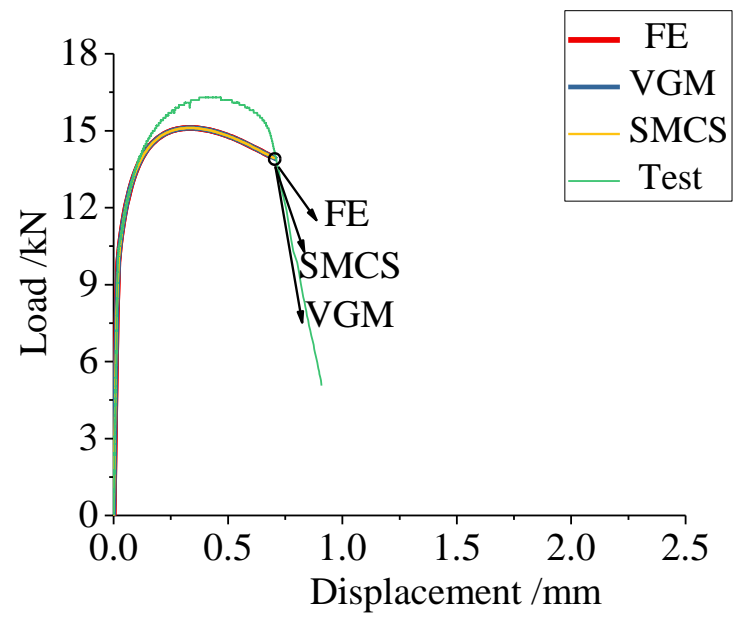

(f) $\mathrm{BSMH}$

Fig. 24 Base metal prediction

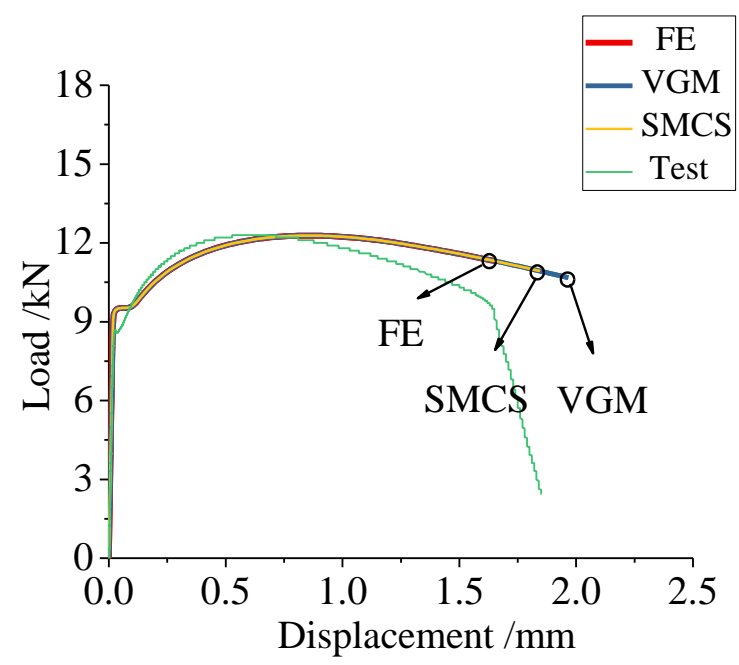

(a) WLML

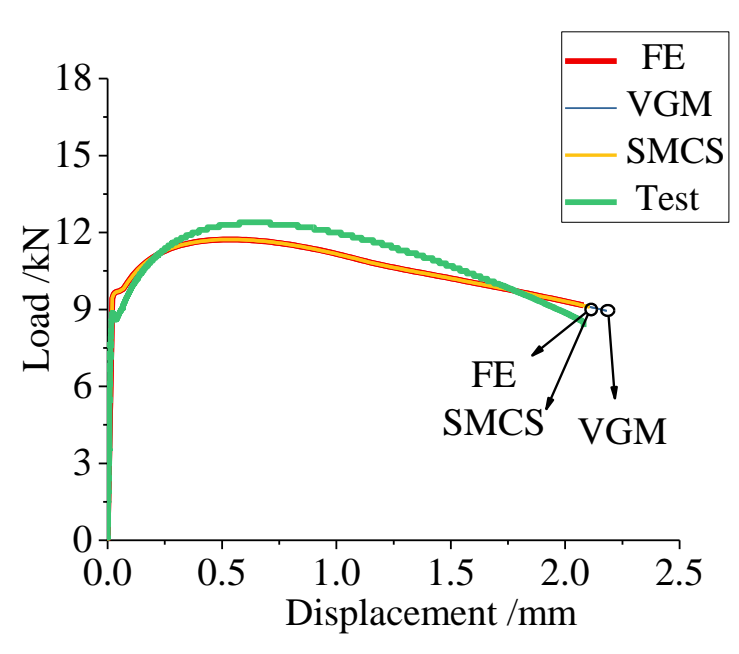

(b) WLMH 


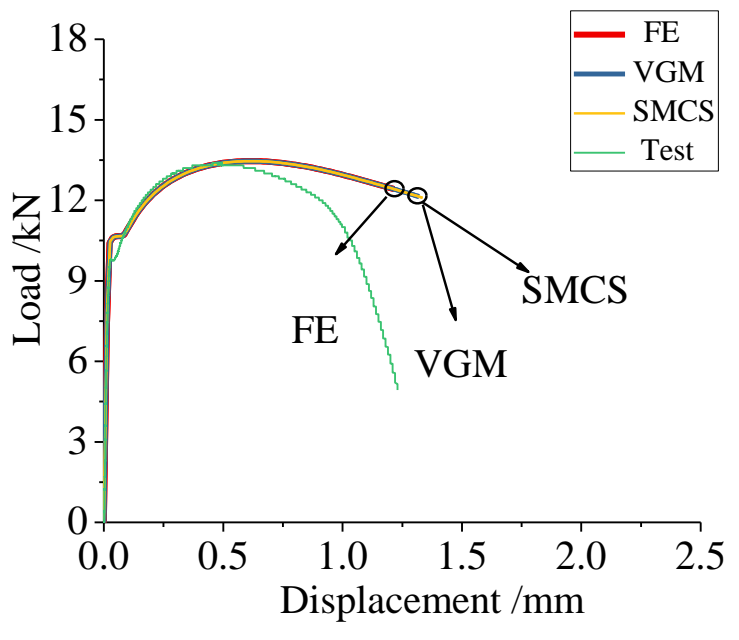

(c) WMML

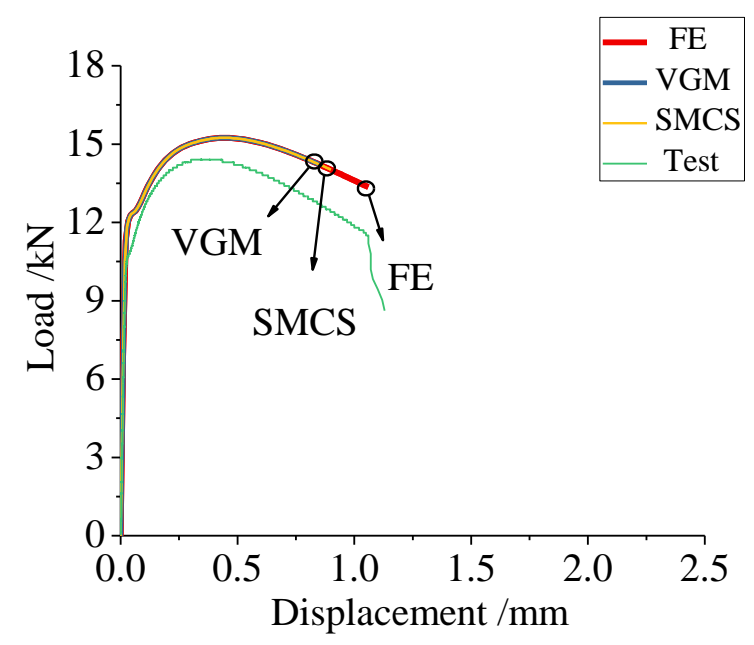

(e) WSML

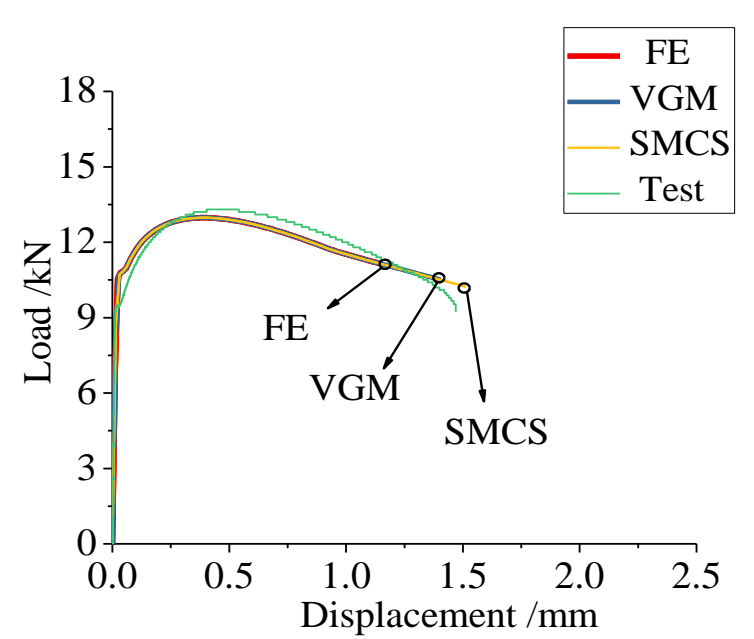

(d) WMMH

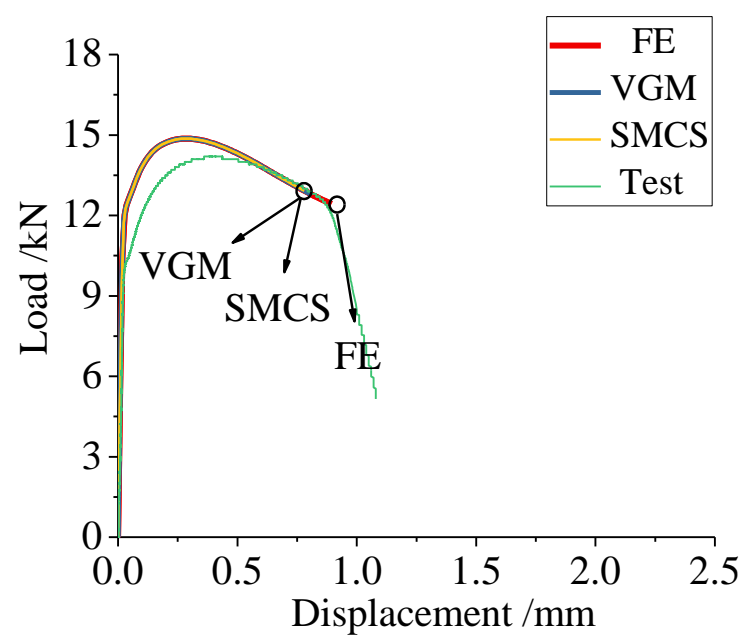

(f) WSMH

Fig. 25 Weld metal prediction

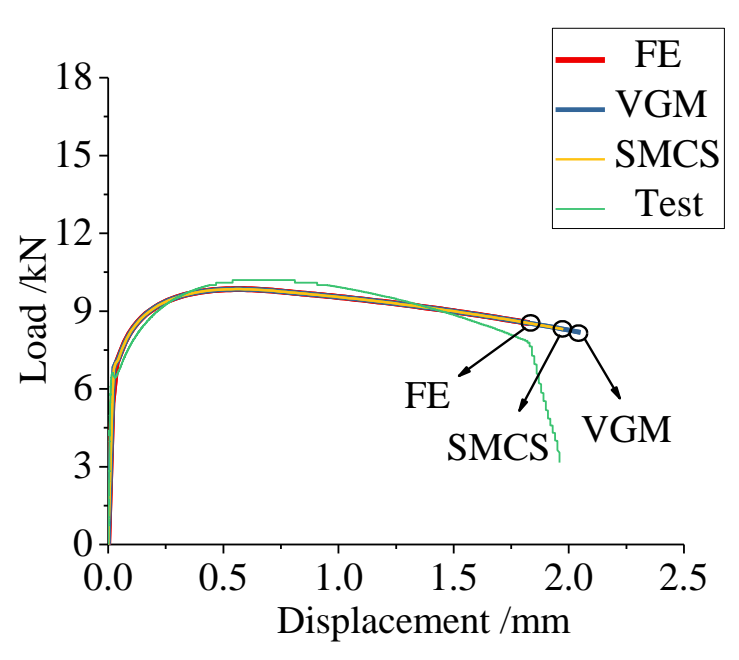

(a) HLML

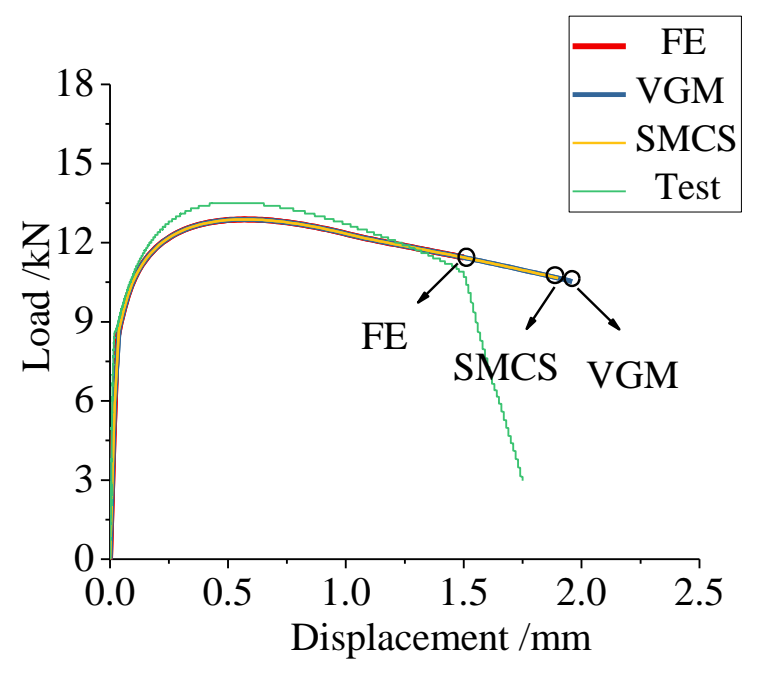

(b) HLMH 


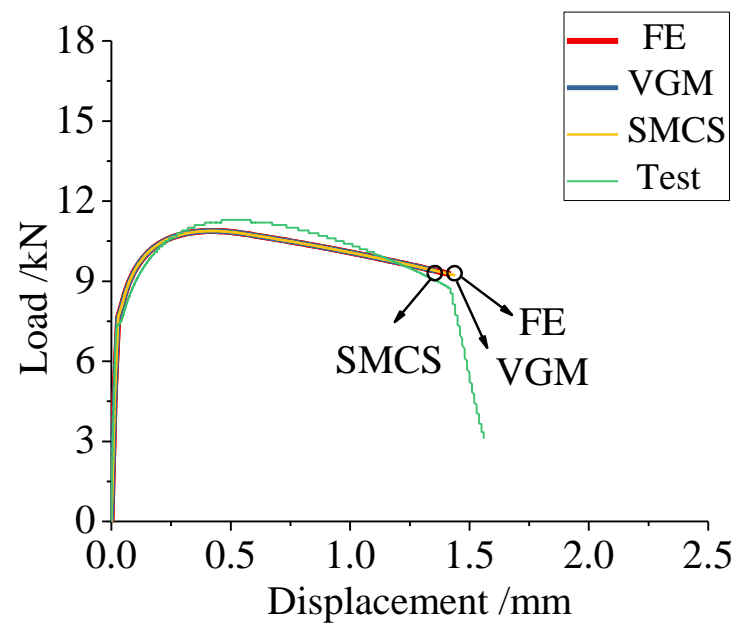

(c) HMML

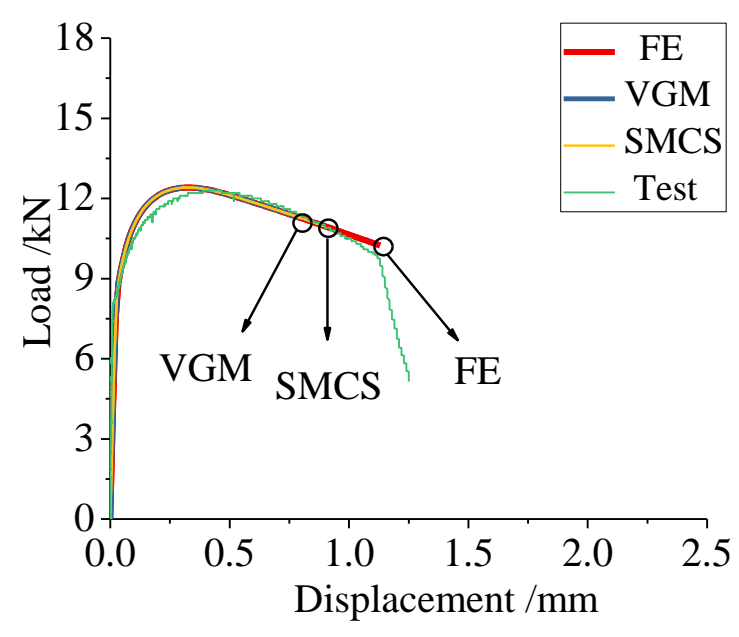

(e) HSML

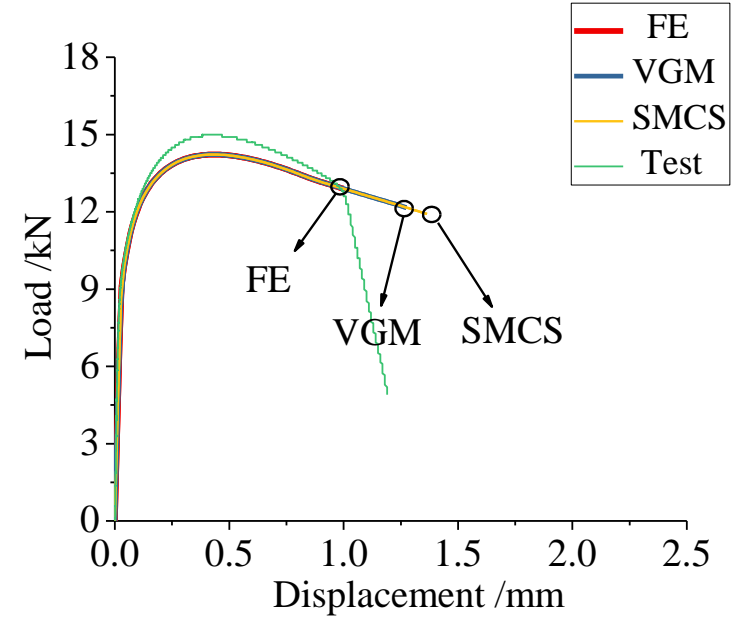

(d) HMMH

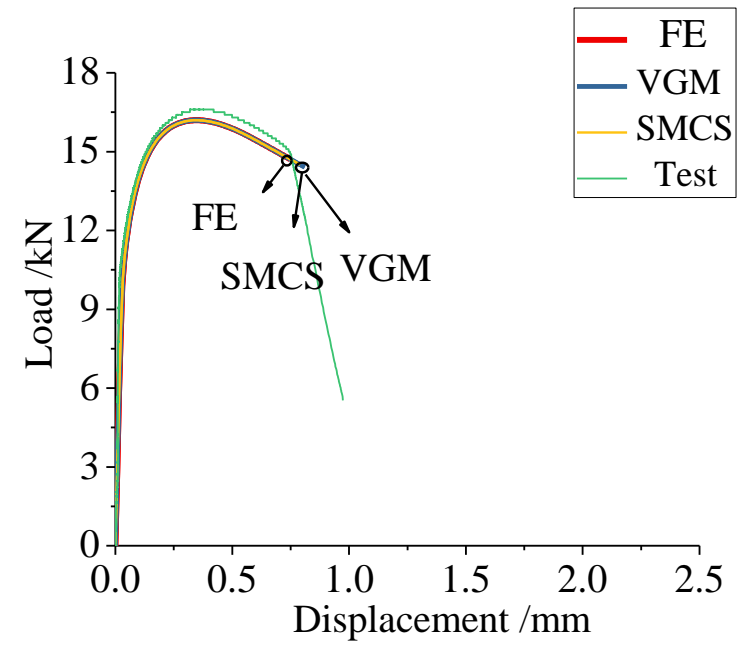

(f) $\mathrm{HSMH}$

Fig. $26 \mathrm{HAZ}$ prediction

Table 11

Fracture load comparisons $(\mathrm{kN})$

\begin{tabular}{|c|c|c|c|c|c|}
\hline Specimen ID & Test & SMCS Prediction & (SMCS-Test) $/$ Test $\%$ & VGM Prediction & (VGM-Test) $/$ Test $\%$ \\
\hline BLMH & 9670 & 10373.70 & 7.28 & 10486.60 & 8.44 \\
\hline BLML & 8250 & 8123.20 & -1.54 & 8064.87 & -2.24 \\
\hline BMMH & 11200 & 11838.10 & 5.70 & 11778.70 & 5.17 \\
\hline BMML & 9300 & 9123.40 & -1.90 & 9032.93 & -2.87 \\
\hline BSMH & 14700 & 13924.50 & -5.28 & 13888.10 & -5.52 \\
\hline BSML & 10400 & 10724.50 & 3.12 & 10590.50 & 1.83 \\
\hline WLMH & 8310 & 8946.89 & 7.66 & 9100.04 & 9.51 \\
\hline WLML & 9480 & 10926.50 & 15.26 & 10672.60 & 12.58 \\
\hline WMMH & 11400 & 10231.10 & -10.25 & 10504.80 & -7.85 \\
\hline WMML & 11344 & 12096.50 & 6.64 & 12137.90 & 7.00 \\
\hline WSMH & 12100 & 12925.20 & 6.82 & 12785.00 & 5.66 \\
\hline WSML & 11500 & 14019.80 & 21.91 & 14200.60 & 23.48 \\
\hline HLMH & 10900 & 10655.30 & -2.24 & 10527.90 & -3.41 \\
\hline HLML & 7780 & 8305.35 & 6.75 & 8182.78 & 5.18 \\
\hline НMМH & 12700 & 11914.70 & -6.18 & 12163.00 & -4.23 \\
\hline HMML & 8740 & 9219.70 & 5.49 & 9385.77 & 7.39 \\
\hline HSMH & 15000 & 14510.90 & -3.26 & 14417.50 & -3.88 \\
\hline HSML & 9750 & 10957.40 & 12.38 & 11262.40 & 15.51 \\
\hline
\end{tabular}




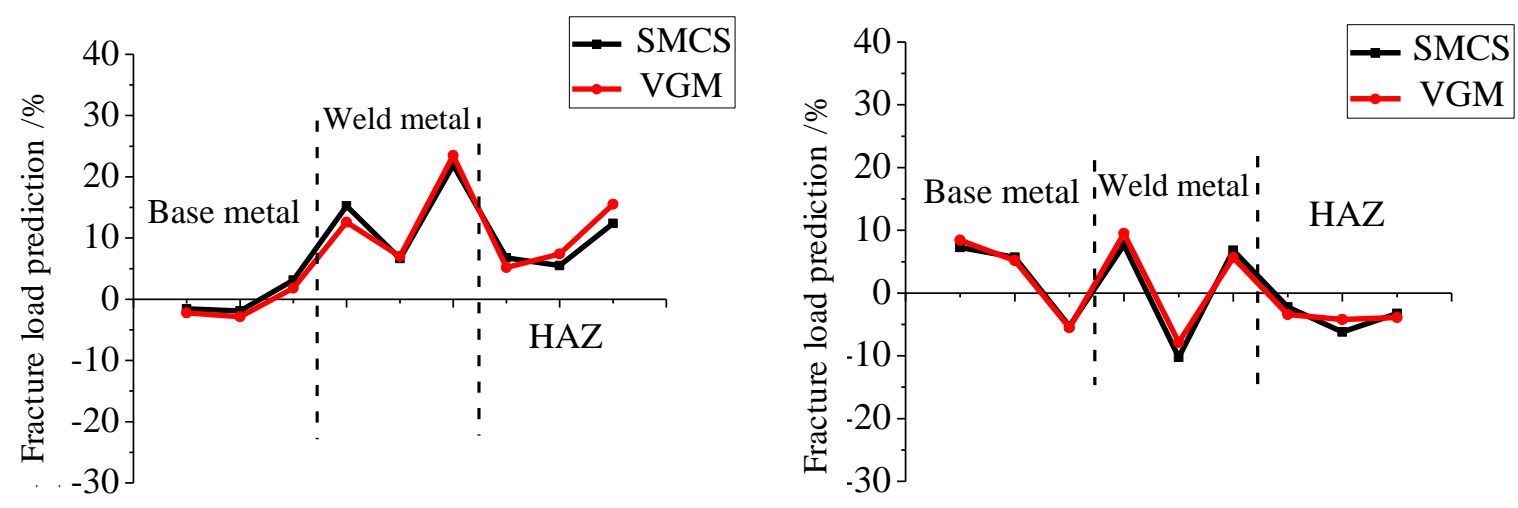

(a) Q235B

(b) Q345B

Fig. 27 Fracture load prediction

Table 12

Fracture displacement comparisons (mm)

\begin{tabular}{|c|c|c|c|c|c|}
\hline Specimen ID & Test & $\begin{array}{c}\text { VGM displacement of } \\
\text { prediction }\end{array}$ & (VGM-Test)/Test $\%$ & $\begin{array}{c}\text { SMCS displacement of } \\
\text { prediction }\end{array}$ & (SMCS-Test) $/$ Test $\%$ \\
\hline BLMH & 1.790 & 1.726 & -3.60 & 1.806 & 0.89 \\
\hline BLML & 1.660 & 2.076 & 25.06 & 2.026 & 22.05 \\
\hline BMMH & 1.150 & 1.125 & -2.17 & 1.095 & -4.78 \\
\hline BMML & 1.270 & 1.335 & 5.12 & 1.395 & 9.84 \\
\hline BSMH & 0.691 & 0.712 & 3.04 & 0.704 & 1.88 \\
\hline BSML & 1.020 & 0.885 & -13.24 & 0.840 & -17.65 \\
\hline WLMH & 2.079 & 2.182 & 4.95 & 2.107 & 1.35 \\
\hline WLML & 1.650 & 1.966 & 19.15 & 1.846 & 11.88 \\
\hline WMMH & 1.152 & 1.404 & 21.88 & 1.512 & 31.25 \\
\hline WMML & 1.216 & 1.320 & 8.55 & 1.335 & 9.77 \\
\hline WSMH & 0.894 & 0.810 & -23.38 & 0.780 & -12.75 \\
\hline WSML & 1.060 & 0.855 & -19.34 & 0.900 & -15.09 \\
\hline HLMH & 1.500 & 1.960 & 30.67 & 1.900 & 26.67 \\
\hline HLML & 1.830 & 2.051 & 12.08 & 1.976 & 8.00 \\
\hline HMMH & 1.000 & 1.275 & 27.50 & 1.365 & 36.50 \\
\hline HMML & 1.420 & 1.360 & -4.23 & 1.440 & 1.41 \\
\hline HSMH-1 & 0.748 & 0.81 & 8.29 & 0.790 & 5.61 \\
\hline HSML-1 & 1.130 & 0.80 & -29.20 & 0.900 & -20.35 \\
\hline
\end{tabular}

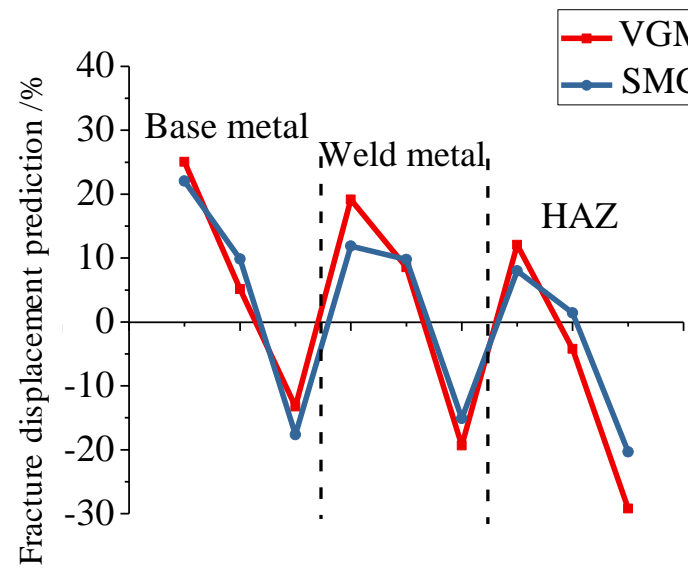

(a) Q235B

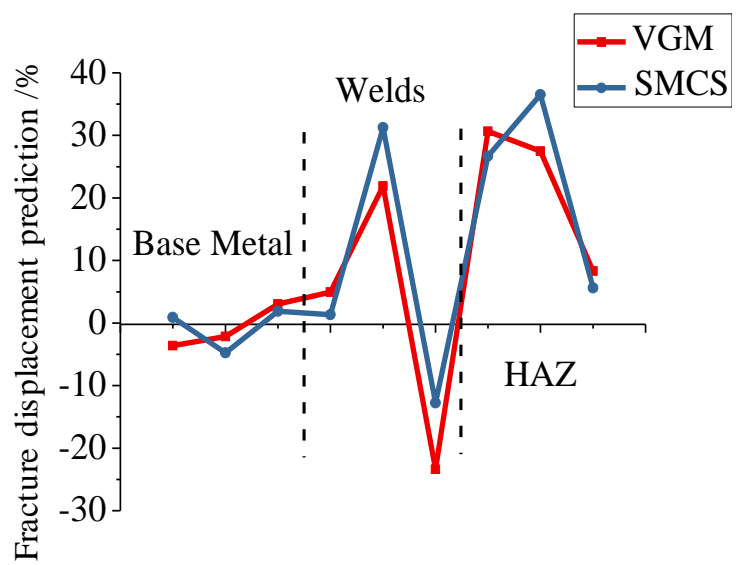

(b) Q345B 
From Fig. 27, it can be seen that both VGM and SMCS model offer good predictions of the failure loads for Q235B and Q345B, especially for the base metal. While the predictions of the weld metal and heat affected zone are more scattered, which might be attributed to the welding effect. Fig. 28 shows that both models offer the fracture displacement prediction within $25 \%$ for base metal, yet the weld metal and HAZ reveals larger level of scatter. In general, VGM model and SMCS model are shown to be applicable to predict the ductile fracture of ordinary steel under different stress states, while for welding seam and HAZ scatter should be expected.

\section{Conclusions}

In this paper 12 smooth round bars and 36 notched round bars were tested under axial tensile load. The fracture behaviour of the base material, the weld metal and the HAZ of welded structural steels Q235B and Q345B were investigated. Two micromechanical fracture models: void growth model (VGM) and stress modified critical strain model (SMCS) were investigated.

The material toughness parameters $\eta_{\text {mon }}$ and $\gamma$ of micromechanical fracture models VGM and SMCS for each material, including the base material, the weld metal and the HAZ of Q235B and Q345B structure steel were calibrated by the tests results. Finite element analysis integrated with the micromechanical models were carried out to simulate the fracture behaviour of these tested specimens. Fracture index distributions show that the fracture initiated from the centre of the specimens, which coincides with the SEM measurements. Upon calibrations, the two models were used to predict the fracture load and displacement and the predictions were compared with the test results. The comparisons show that VGM model and SMCS model offer accurate ductile fracture prediction for the base metal under different stress states, while for welding seam and HAZ scatter should be expected.

\section{Compliance with Ethical Standards:}

Funding: This study was funded by the National Natural Science Foundation of China (No. 51678339 and No.51708549).

Conflict of interest: The authors declared that they have no conflicts of interest to this work.

\section{Reference}

[1] F. A. McClintock, A criterion for ductile fracture by the growth of holes. Journal of Applied Mechanics. 35 (2) (1968) 363-371.

[2] J. R. Rice, D. M. Tracey, On the ductile enlargement of voids in triaxial stress fields. Journal of Mechanics and Physics of Solids. 17 (3) (1969) 201-217.

[3] J. W. Hancock, A. C. Mackenzie, On the mechanics of ductile failure in high-strength steel subjected to multi-axial stress states. Journal of the Mechanis and of Physics of Solids. 24 (3) (1976) $147-169$.

[4] J. W. Hancock, M. J. Cowling, Role of state of stress in crack-tip failure processes, Metal Science. 14 (8-9) (1980) 293-304.

[5] J. W. Hancock, D. K. Brown, On the role of strain and stress state in ductile failure. Journa of the Mechanics \& Physics of Solids, 31 (1) (1983) 1-24.

[6] G. R. Johnson, W. H. Cook, A constitutive model and data for metals subjected to large strains, high strain rates and high temperatures. Proceedings of the 7th International Symposium on Ballistics, The Hague. (1983) 541-547.

[7] B. Marini, F. Mudry, A. Pineau. Ductile rupture of A508 steel under nonradial loading. Engineering Fracture Mechanics. 22 (3) (1985) 375-386.

[8] T. L. Panontin, S. D. Sheppard. The relationship between constraint and ductile fracture initiation as defined by micromechanical analyses, Fracture Mechanics. (1995), 54-85.

[9] J. P. Bandstra, D. A. Koss. A simulation of growth and coalescence of voids during ductile fracture. Materials Science \& Engineering A. 387 (1) (2004) 399-403.

[10] A. M. Kanvinde, G. G. Deierlein. Void growth model and stress modified critical strain model to predict ductile fracture in structural steels. Journal of Structural Engineering. 132 (12) (2006) 1907-1918

[11] W. M. Chi, A. M. Kanvinde, G. G. Deierlein, Prediction of ductile fracture in steel connections using SMCS criterion. Journal of Structural Engineering. 132 (2) (2006) $171-181$.

[12] A. A. Benzerga, Micromechanical Models of Ductile Damage and Fracture. Springer New York. (2015) 939-962.

[13] A. T. Myers, G. G. Deierlein, A. M. Kanvinde, Testing and probabilistic simulation of ductile fracture initiation in structural steel components and weldments. Report No.170, the John A.Blume Earthquake Engineering Center, Stanford University, CA, 2009.

[14] Y. Q. Wang, H. Zhou, Y. J. Shi, J. Xiong, Fracture prediction of welded steel connections using traditional fracture mechanics and fracture mechanics and calibrated fracture mechanics and calibrated micromechanics-based model. International Journal of Steel Structures. 11 (3) (2011) 351-366.

[15] P. G. Kossakowski, Prediction of ductile fracture for S235JR steel using the stress modified critical strain and Gurson-Tvergaard-Needleman models. Journal of Materials in Civil Engineer. 24 (12) (2012) 1492-1500.

[16] F. F. Liao. Criterion of micro-cracking criterion of steel and its application in prediction of ductile fractures at nodes (in Chinese)..Shanghai, Tongji University, 2012.

[17] R. Kiran, K, Khandelwal, Experimental studies and models for ductile fracture in ASTM A992 steels at high triaxiality. Journal of Structural Engineering, ASCE. 140 (2) (2013) $1-48$.

[18] X. Y. Liu, Study on fracture property of high strength steel structure materials and joints based on microscopic mechanism. Beijing, Tsinghua University, 2015.

[19] L. Lu, Experiment and analysis of ductile fracture of steel based on microscopic mechanism.
Nanjing, Southeast University, 2015

[20] GB/T 228.1-2010. Metallic materials-Tensile testing -Part 1: Method of test at room temperature (in Chinese). Beijing: Standards Press of China, 2010.

[21] B. Xiao, L. Xu, L. Zhao, H. Jing, Y. Han, Z. Tang, Microstructure evolution and fracture mechanism of a novel $9 \mathrm{Cr}$ tempered martensite ferritic steel during short-term creep. Materials Science and Engineering. A. (2017) 466-477.

[22] A. M. Kanvinde, G. G. Deierlein, Micromechanical simulation of earthquake-induced fracture in steel structures. Report No.145, the John A. Blume Earthquake Engineering Center, Stanford University, CA, 2004. 